\title{
Delineating recurrent fish spawning habitats in the North Sea
}

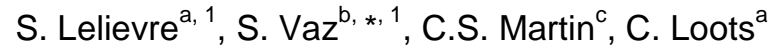 \\ a Ifremer, Fisheries Ressources Laboratory, Boulogne sur Mer, France \\ ${ }^{\mathrm{b}}$ Ifremer, Mediterranean Fishery Unit, Sète, France \\ ${ }^{\mathrm{c}}$ United Nations Environment Programme World Conservation Monitoring Centre, Cambridge, UK \\ ${ }^{1}$ The first two authors contributed equally to this study \\ *: Corresponding author : S. Vaz, email address : Sandrine.vaz@ifremer.fr \\ Stephanie.lelievre@live.fr ; corinne.martin@unep-wcmc.org; christophe.loots@ifremer.fr
}

\begin{abstract}
:
The functional value of spawning habitats makes them critically important for the completion of fish life cycles and spawning grounds are now considered to be "essential habitats". Inter-annual fluctuations in spawning ground distributions of dab (Limanda Limanda), plaice (Pleuronectes platessa), cod (Gadus morhua) and whiting (Merlangius merlangus) were investigated in the southern North Sea and eastern English Channel, from 2006 to 2009. The preferential spawning habitats of these species were modelled using generalised linear models, with egg distribution being used as proxy of spawners' location. Egg spatial and temporal distributions were explored based on six environmental variables: sea surface temperature and salinity, chlorophyll a concentration, depth, bedstress and seabed sediment types. In most cases, egg density was found to be strongly related to these environmental variables. Egg densities were positively correlated with shallow to intermediate depths having low temperature and relatively high salinity. Habitat models were used to map annual, i.e. 2006 to 2009, winter spatial distributions of eggs, for each species separately. Then, annual maps were combined to explore the spatial variability of each species' spawning grounds, and define recurrent, occasional, rare and unfavourable spawning areas. The recurrent spawning grounds of all four species were located in the south-eastern part of the study area, mainly along the Dutch and German coasts. This study contributes knowledge necessary to the spatial management of fisheries resources in the area, and may also be used to identify marine areas with particular habitat features that need to be preserved.
\end{abstract}

\section{Highlights}

The spawning ground distributions of dab, plaice, cod and whiting are explored from 2006 to 2009 in the North Sea Spawning habitat models are developed by relating egg density to six environmental descriptors - Predicted annual habitat maps highlight suitable spawning areas and their spatial variability Recurrent spawning grounds are delineated for each species - Most suitable and temporally stable spawning areas are defined for use in marine spatial planning 
Keywords : egg distribution ; spawning grounds ; North Sea ; temporal variability ; habitat modelling ; GLM

\section{Introduction}

Fish spawning takes place in spatially limited areas (or grounds) with attributes that favour reproductive success through higher egg survival (Bellier et al., 2007 and Planque et al., 2004). Areas offering favourable environmental conditions often correspond to frontal zones (Munk et al., 2002 and Munk et al., 2009), which are transitional areas between water masses, such as upwellings, areas affected by tides, river plumes or estuaries (Bakun, 1996 and Munk and Nielsen, 2005). Monitoring fish spawning grounds has been identified as one of the key steps for an ecosystem-based approach to marine management (Anon, 2002). Spawning can indeed be affected by, and reflect, adult stock depletion, habitat disturbance, climate change and other processes (Begg and Marteinsdottir, 2002 and Rijnsdorp et al., 2009). Moreover, knowledge of the location and extent of fish spawning areas is also required for environmental risk assessment in the case of industrial developments, such as offshore energy and aggregate extraction for sand and gravel (Stelzenmüller et al., 2010). Therefore, knowledge and 
preservation of spawning grounds are essential for interpreting fish stock fluctuations, improving the management of stocks and hence maintaining appropriate population levels.

The eastern English Channel and North Sea sustain one of the richest commercial fisheries in the world, in terms of both diversity and abundance. These areas are also ecologically important, due to a number of fish spawning and nursery areas (ICES, 2009; Martin et al., 2009). Many fish species display a year to year consistency in their spawning location, thereby reflecting a certain fidelity to particular grounds (Daan, 1981; Fox et al., 2000; Fox et $a l ., 2008)$, and suggesting the existence of preferential spawning habitats. The frontal zones to which egg distributions are often linked may, however, vary from year to year (Munk et al., 1999). Repeated in situ observations are an effective approach to study the spatio-temporal variability of fish spawning habitats (Bellier et al., 2007), and can be carried out at high spatial resolution using the Continuous Underway Fish Egg Sampler (CUFES; Checkley et al. 1997). This way, grounds that are repeatedly used for laying eggs can be identified and delineated. The CUFES is relatively easy to operate and provides reliable estimates of egg abundance (Lo et al., 2001) and distribution (e.g. sardine, Sardina pilchardus and whitehead's round herring, Etrumeus whiteheadi; van der Lingen et al., 1998). It has successfully been used to map egg distribution and spawning grounds of pelagic fish species (Petitgas et al., 2006; Lelièvre et al., 2012a).

Habitat may be defined as geographical locations where biotic and abiotic conditions allow presence, or favour abundance, of a given fish species at a given life stage (Benaka, 1999). A number of statistical modelling techniques are available to predict species habitats (Guisan et al., 2006; Planque et al., 2011). For instance, Generalised Linear Models (GLM; McGullach and Nelder, 1989) belong to the family of linear regressions, and can be used to model the mean of response data that are not necessarily normally distributed. This approach consists in generating a model that summarises the relationship between a species' presence, or abundance, and a set of explanatory environmental variables. The model can then be used to predict the species' average distribution, using that of the environmental variables in the model (Martin et al., 2012).

The present study aimed to explore spawning grounds' spatio-temporal dynamics in the eastern English Channel and southern North Sea. Here, the focus is on four fish species, all of 
commercial importance: dab (Limanda limanda), plaice (Pleuronectes platessa), cod (Gadus morhua) and whiting (Merlangius merlangus). These species spawn between January and June, with peaks in January for plaice (Simpson, 1959), February for cod, and March for whiting and dab (Munk and Nielsen, 2005). GLMs, coupled with a Geographic Information System (GIS), were used to map annual spawning habitats of each species, based on environmental variables. Then, the temporal variability of these habitats was assessed to define recurrent spawning areas, considered as the core of the spawning ground, i.e. where spawning takes place every year. Finally, areas deemed to be of upmost conservation value were delineated, based on the recurrent spawning habitats of dab, plaice, cod and whiting together.

\section{MATERIALS AND METHODS}

\subsection{Sampling surveys}

The International Bottom Trawl Survey (IBTS) takes place annually in the North Sea and part of the eastern English Channel (Fig. 1) to estimate stock abundance and recruitment level of the main exploited fish species (ICES, 2004). Taking advantage of the survey's path, data on fish eggs and environmental variables were collected from 2006 to 2009 (January, February), on-board $R V$ Thalassa (Table 1).

\subsection{Biological data}

The four species investigated in this study spawn pelagic eggs that may drift with currents (Bunn et al., 2000). Under calm conditions, eggs are expected to accumulate close to the surface, showing a clear peak in abundance in the upper layer (up to $20 \mathrm{~m}$ depth) (Conway et al., 1997; Adlandsvik et al., 2001, Pépin et al., 2005). Using CTD profiles and vertical egg tows, Lelièvre et al., 2012a have shown that in the southern North Sea, strong currents and winter wind conditions generally result in a well-mixed water column, so CUFES samples are usually representative of egg density over the entire water column. Although the CUFES alone cannot be used for a precise estimation of total egg density, it was shown to accurately depict the spatial distribution of eggs under the conditions of the present study.

Sub-surface samples were collected using the CUFES, which continuously pumped water $5 \mathrm{~m}$ below the surface, through a $5 \mathrm{~cm}$ diameter inlet protruding slightly from the hull and pumping water perpendicularly to the current. To enhance the catching efficiency, a metallic 
scoop was bolted on the side of the ship and was directed into the current. Samples were filtered over a mesh size of $500 \mu \mathrm{m}$, and collected every 30 minutes. For each sample, the volume of filtered water was determined using both sampling duration and the pump's recorded flow rate. Samples were fixed in a $0.9 \%$ buffered formalin seawater solution (Mastail and Battaglia, 1978; Lelièvre et al., 2010a). Fish eggs were identified to species level, under a stereomicroscope (Leica MZ6), based on their size, the presence of oil globules and their degree of pigmentation (Russell, 1976; Munk and Nielsen, 2005). Species misdentification based on egg morphology is possible, but misidentification rates measured by molecular analyses were found to be small (7\% for dab and $2 \%$ and $29 \%$ for cod and whiting respectively; Lelièvre et al., 2010a, Lelièvre et al., 2012b). Eggs were sorted into developmental stages and only stage 1 eggs (showing no embryo) were used for the present study as they were considered to accurately depict the location of the spawning grounds. Indeed, as this first developmental stage only lasts for two days or a little longer depending on temperature (Russell, 1976, Thompson and Riley, 1981, Ryland and Nichols, 1975) and as the retention time is high in the southern North Sea despite locally high tidal- and wind-induced currents (Maier-Reimer, 1977), such eggs were not expected to have significantly drifted away from their point of emission. Egg abundance (x) was then expressed as densities for a standard volume of $20 \mathrm{~m}^{3}$ (close to that filtered during the $30 \mathrm{~min}$ sampling time), and log transformed $\left(\log _{10}(\mathrm{x}+1)\right)$ (Legendre and Legendre, 2012).

\subsection{Environmental data}

Six environmental variables were tested as predictors in habitat modelling (Fig. 3): sea surface temperature $\left({ }^{\circ} \mathrm{C}\right)$ and salinity (PSU), chlorophyll $a$ concentration $\left(\mu \mathrm{g} .1^{-1}\right)$, depth $(\mathrm{m})$, seabed sediments type and bedstress $\left(\mathrm{N} . \mathrm{m}^{-2}\right)$. Surface temperature, salinity and chlorophyll $a$ were continuously measured using a sub-surface (3-5 m) thermosalinometer and a fluorometer, respectively. Depth (m) was recorded using the vessel's sonar system. Seabed sediment types were extracted from Larsonneur et al. (1982) and Schlüter and Jerosch (2009), and reclassified into five broad categories: mud, fine sand, coarse sand, gravel and pebbles. Bedstress, a measure of friction on the seabed as a result of tidal currents, was estimated using a 2D hydrodynamic model, originally developed at the Proudman Oceanographic Laboratory (Aldridge and Davies, 1993). Although sediment type and bed stress may seem to bear no direct ecological relationship to pelagic fish eggs (presence and/or abundance), they are believed to be relevant proxies to the spatial distribution of demersal spawners. The latter certainly conditions the observed distribution of stage 1 eggs. Explanatory variables were 
tested for collinearity, based on correlation coefficients and variance inflation factor (Zuur et al., 2007).

\subsection{Habitat modelling}

\subsubsection{Model development}

Spatially correlated data are not independent, which results in inflated rates of type I error, misspecification of the number of degrees of freedom and inaccurate, often over-fitted, models (Dormann, 2007). Data generated by continuous sampling tend to be highly autocorrelated, which disproportionately inflates the explanatory power of these variables, at the expense of potentially more important variables (Segurado et al, 2006). Although a number of methods can be used to incorporate a term of contagion encompassing the effect of spatial autocorellation in the analyses (Dorman et al., 2007), these methods may overcompensate for avoiding the inflation effect (Kissling and Carl, 2008). An alternative procedure to avoid this pseudoreplication phenomenon is to subsample the original data by adopting a systematic scheme that constrains observations to be interspaced enough from each other (Segurado et al., 2006). This approach was preferred here as the large size of the available dataset easily permitted it. Based on a series of correlograms, it was found that a separation distance of 0.6 decimal degrees (dd) of latitude between observations was sufficient to remove autocorrelation. Three different sampling grids (A, B, and C) were hence created, each with a mesh size of 0.6 dd (Table 1), and used for model development (Fig. 2). Dataset D, shown in Fig. 2 and kept for model validation, gathered all observations not used for datasets A, B and C.

GLMs are flexible in that they can be applied to data that are not necessarily normally distributed. Bedstress, chlorophyll $a$ concentration and depth were nevertheless logtransformed, and so was salinity (using $\exp (\mathrm{x}) / 10^{15}$ ), so as to improve the linearity of their relationship with egg density. Seabed sediments types (a categorical variable) were tested in the modelling procedure as factors, whilst the five other variables (of continuous nature) were tested as first and second order polynomial forms, as data exploration plots suggested that the shape of species-environment relationships would often be better described as curvilinear.

Histograms of egg densities highlighted a discontinuity between the zero values and positive density data. A two step modelling procedure was hence adopted, whereby the presence of eggs was modelled separately from their density level (Stefánsson, 1996; Barry and Welsh, 
2002; Lauria et al. 2011). Presence-absence data were modelled using a binomial model with a logit link. Non null (log-transformed) densities were modelled using a Gaussian model with identity link function (McCullagh and Nelder, 1989), to predict the mean density on a log scale.

Datasets A, B and C were used, each in turn, to select the models' explanatory variables and estimate the models' parameters. Starting from an initial full model containing all the variables as main effects, predictors were removed by backward elimination, first by minimising the Akaike's Information Criterion (AIC; Akaike, 1974; Sakamoto et al., 1986), and then the Bayesian Information Critetion (BIC; Schwarz, 1978). The same procedure was repeated starting from an initial full model containing all variables expressed in their second order polynomial forms. This procedure resulted, for each species, in 36 (i.e. 18 binary and 18 Gaussian) different model parameterisations,including the initial full models (see Supplementary Material).

\subsubsection{Model selection}

To quantitatively assess the models' predictive power, their 18 predictions were compared with observed values in dataset $\mathrm{D}$, using a range of diagnostic measures. In the case of binomial models, the Receiver Operating Characteristic (ROC) curve (Guisan and Zimmermann, 2000) showing the trade off between prediction sensitivity and specificity was computed, and the Area Under that Curve (AUC) was calculated. For Gaussian models, the Mean Absolute Error (MAE) was calculated. For both model types, the coefficient of determination $\left(\mathrm{R}^{2}\right)$ was also computed (Legendre and Legendre, 2012) and models were ranked according to these three measures. The 'final' binomial model would be the one with highest $\mathrm{R}^{2}$ and AUC values, while the 'final' Gaussian model would be the one with highest $\mathrm{R}^{2}$ value and lowest MAE value.

\subsubsection{Model evaluation}

Each final model was further evaluated with complementary measures. Model fit was assessed using the adjusted coefficient of determination (Adj-R²; Legendre and Legendre, 2012). In the case of Gaussian models, Spearman's rank correlation tests investigated whether there was a positive and significant correlation between observed and predicted values, whilst Wilcoxon signed-rank tests compared the mean and variance of observed and predicted densities (Wilcoxon, 1945) to assess whether there was a significant difference between observed and 
predicted values' distribution ranges. Finally, Moran's I correlogram was used to test the significance level of spatial autocorrelation in the models' residuals, with separation distance class equal to $0.8^{\circ}$ (to insure full connectivity) and over 10 lags (to cover the entire study area) (Diniz-Filho et al., 2003; Bocard et al., 2011). Holm's correction of p-value was applied (Bocard et al., 2011).

\subsubsection{Combining binary and Gaussian predictions (delta model)}

For each species, the final binary model (predicting presence probability) was combined to the final Gaussian model (predicting density level on a log scale) by multiplying their prediction values into a final, so-called, delta habitat model illustrating the species' egg density conditioned to its presence (Barry and Welsh, 2002). Predicted probabilities of presence were first transformed into presence-absence data based on a threshold probability indicative of species presence. This threshold was determined by comparing the confusion matrices between observed and predicted values in the full dataset (i.e. datasets $A+B+C+D$ ). Specificity was calculated as the ratio of correctly predicted absences to the total number of absences, and sensitivity as the ratio of correctly predicted presences to their total number. Two optimising criteria were considered: (1) minimising the difference between sensitivity and specificity (MDS) and (2) maximising the sum of sensitivity and specificity (MSS) (Jimenez and Lobo, 2007). When the thresholds determined by these two methods were not equal, the lowest threshold was used to lower the omission error rate.

For each species, the delta model's behaviour was assessed over the entire available dataset $(\mathrm{A}+\mathrm{B}+\mathrm{C}+\mathrm{D})$ by comparing predicted and observed egg densities using Adj- $\mathrm{R}^{2}$, Spearman's rank correlation and Wilcoxon signed-rank tests. In order to provide confidence intervals for these measurements, 1,000 bootstrapped datasets were also generated.

Delta models implicitly account for interactions between explanatory variables, and may be difficult to assess. So as to facilitate ecological interpretation of the delta models, their behaviours along each relevant environmental gradient were plotted. Predicted values were shown as boxplots against observed values, so as to graphically examine the effect of the combination of binomial and Gaussian models on the shape of the relationship to each explanatory variable. Overall prediction errors were computed for each final delta model as the absolute standardised residuals from a linear regression between predicted and observed egg densities. 
The packages car (Fox and Weisberg, 2011), MASS (Venables and Ripley, 2002), boot (Canty and Ripley, 2012; Davison and Hinkley, 1997), verification (Research Application Program, 2012), PresenceAbsence (Freeman and Moisen, 2008), spdep (Bivand et al., 2012) were used in R (R Development Core Team, 2009), to carry out the analyses described above.

\subsubsection{Annual habitat maps derived from the delta models}

Maps of the six environmental variables were either readily available (i.e. sediment, depth), or produced by kriging interpolation (i.e. bedstress, and in situ surface temperature, salinity and chlorophyll $a$ concentration for each year between 2006 and 2009). Figure 3 shows these maps, although average values are shown for surface temperature, salinity and chlorophyll $a$ concentration. For each species and each year between 2006 and 2009, the delta model was mapped within a Geographic Information System (ESRI ArcGIS 9.1) by applying the regression coefficients of the binomial and Gaussian models to the maps of the corresponding set of environmental variables. The presence-absence threshold was applied to the "presence probability' map (corresponding to the binary model), which was then multiplied to the 'egg density' map (corresponding to the Gaussian model), thereby resulting in one 'habitat map' per species and per year (i.e. 16 in total; Stefánsson, 1996; Barry and Welsh, 2002; Le Pape et $a l ., 2003)$. Maps of the prediction errors were produced by interpolation in order to illustrate their spatial patterns.

\subsection{Fluctuation in spawning location}

The annual habitat maps (created in section 2.4.5) were used to explore inter-annual variability in spawning location for each species between 2006 and 2009. In each annual habitat map, egg density predictions were rescaled to range between 0 and 1 . Then, for each species separately, the four rescaled maps were averaged (referred to as "average map"), and a standard deviation estimated (referred to as "variability map"), within a GIS. Finally, the average and variability maps were combined in order to identify four categories of spawning areas (referred to as "habitat type"; Bellier et al., 2007): (1) recurrent spawning areas, where spawning is observed every year (high mean and low standard deviation); (2) occasional, where the spawning occurrence varies greatly from year to year (high mean and standard deviation); (3) rare (low mean and high standard deviation); and (4) unfavourable (low mean and standard deviation) spawning areas, where spawning is almost never observed. The 
median values of both the average and variability maps were used as splitting thresholds between high and low values.

\subsection{Delineating multi-species spawning areas}

In order to identify zones of the study area that could be of conservation and management interests, a multi-specific habitat map was created, combining the habitat patterns of the four species considered. This was done by summing the four "average maps", one for each species (see section 2.5), resulting in the combined potential spawning ground of all four species.

In parallel, the recurrent spawning areas of each species were set to 1 , and the other habitat categories (i.e. occasional, rare or unsuitable) to zero: the four resulting binary maps were summed to highlight the core spawning grounds effectively used every year by all four species.

\section{RESULTS}

\subsection{Habitat modelling}

Relationships between the six environmental variables were explored (Table 2) and were found not to be collinear (variance inflation factor $<2.5$ ). They were therefore all tested in model development. Only models calibrated with datasets B or C were retained, and final models could contain either all tested environmental variables expressed in their polynomial forms (initial model formulation), or a lesser number of variables, selected by backward selection, using either AIC or BIC (Tables 3, 4 and 5).

Final binomial models had Adj- $\mathrm{R}^{2}$ ranging from 0.03 to 0.33 , depending on the evaluation dataset used, and all AUC values were $>0.7$ (Table 4). In most instances, little $(<0.3)$ or no significant autocorrelation was detected in the models' residuals. Presence-absence cut-off values, determined using MSS criteria, ranged from 0.26 to 0.56 , depending on the species. Final Gaussian models had Adj- $\mathrm{R}^{2}$ ranging from 0.63 to 0.94 (Table 5). Spearman's rank correlations between observed and predicted values were positive and significant in all cases, and no significant difference between them was detected using the Wilcoxon signed-rank test. In most instances, little $(<0.15)$ or no significant autocorrelation was found in the models' residuals. 


\subsubsection{Delta models}

Delta model evaluations are shown in Table 6. For each species, the model's Adj- $\mathrm{R}^{2}$ was found to be relatively high $(>0.80)$. Consistent with this, Spearman's rank correlation coefficients between observed and predicted values ranged between 0.31 and 0.49 ; these coefficients were found to be higher for dab and plaice than for cod and whiting. The Wilcoxon signed-rank test was significant for all species, indicating that there was a difference between observed and predicted means and variances of density. This revealed that the resulting delta models were unable to fully reproduce the observed range of egg density levels. The mean absolute standardised residuals varied between 0.3 and 0.8 .

Fig. 4 illustrates each species' response to each of the environmental variables. Low to intermediate depth, bedstress and temperature constituted optimal environmental conditions, while intermediate to high levels of salinity were found to be suitable for all species investigated. Intermediate to high chlorophyll $a$ concentration seemed unsuitable to most species, but dab. Egg density levels were higher on sand or mud for cod and dab, while plaice and whiting seemed to be more tolerant to coarser sediments.

\subsubsection{Annual habitat maps}

The annual habitat maps (Fig. 5) reflected these differences: the predicted distributions of dab and cod eggs were mainly located off the Belgian, Dutch, German and Danish coasts, and on the Dogger Bank. Plaice spawning habitats were predicted offshore in the central part of the study area, whilst those of whiting were more inshore, near the French coast, and along the Belgian and Dutch coasts. The distribution patterns of the models' errors were very patchy and appeared almost random in areas of high density levels, compared to areas of absence where model error was more evenly distributed.

\subsection{Fluctuation in spawning location}

Average distributions of dab, cod and plaice egg densities (Fig. 6) were found to cover a large part of the study area, located mainly near the Dutch, German and Danish coasts and excluding the northwestern part along and off the British coast. The average distribution of whiting was limited to the southern Bight and off the Norfolk coast. In general, higher temporal variability was located in the eastern part of the southern Bight, on the Dogger Bank and along the coasts of the German Bight. 
Maps of recurrent, occasional, rare and unfavourable spawning areas resulting from the combination of the average and variability maps are also presented in Fig. 6. For dab, plaice and cod, recurrent spawning areas were mainly located in the south-eastern part of the North Sea, off the Dutch, Danish and German coasts. The north-western part of the study area, near the Scottish coast seemed to be an unfavourable spawning habitat for these species. Whiting exhibited spatially-restricted recurrent spawning areas offshore of the three estuaries, and occasional spawning areas near them. The southern Bight was rarely used for spawning, whilst the central North Sea seemed unfavourable for spawning at that time of the year.

\subsection{Multi-specific spawning areas}

The multispecific spawning habitat map (Fig. 7, left) highlighted that suitable winter spawning habitat covered a large area in the south-eastern part of the North Sea, including the entire German Bight and a smaller area to the south of the Dover Strait. These correspond to areas having shallow depth, and intermediate salinity and temperature. Moreover, the spawning recurrence frequency map, combined for all species (Fig. 7, right), highlighted as core spawning areas over the 2006 to 2009 period the Dogger Bank, an offshore area located southeast of it, the whole of the German bight, and a small area located south of the Dover strait.

\section{DISCUSSION}

The present study used GLMs to investigate and map winter spawning habitats of cod, whiting, plaice and dab, based on stage 1 egg density data and a set of environmental variables. For the first time in this area, GIS calculation combined these habitat models with annual environmental maps so as to explore annual fluctuations in habitat use, through the mapping of recurrent, occasional, rare and unfavourable spawning areas. Finally, a multispecific integration of these results was performed to designate the most important areas for winter spawning in the southern part of the North Sea.

\subsection{Strengths and weaknesses of the modelling approach}

The modelling methodology developed for the present study was inspired by multi-model approaches (Burnham and Anderson, 2002; Loots et al., 2010a; Planque et al., 2011): a single final model was selected based on its predictive power, which was evaluated using an independent dataset. For the eight final models (two by species), only datasets B and C were retained for model calibration. Although slightly larger, dataset A did not seem to contain 
enough information to adequately parameterise the models. This result revealed that the approach taken, of developing models using three different calibration datasets, was more precautionary and avoided overlooking important parts of information when sub-setting the full dataset (Legendre and Legendre, 2012). In many instances, the full model was retained, showing that removing variables would negatively impact the predictive power of the models. Besides, BIC-based model selection was often found to yield better results than model selection based on AIC; BIC model selection is often preferred to AIC, when the aim is to select more parsimonious models (Wagenmakers and Farrell, 2004).

Binomial models' performances, measured using AUC, often resulted in relatively good results (AUC>0.7), regardless of the dataset used (development or independent). Adj- $\mathrm{R}^{2}$ of binomial models remained lower than expected, suggesting limited explanatory power, especially for whiting. This was further highlighted by the very low presence-absence cut-off value retained for this species, for which eggs were in fact observed at low levels over most of the study area. It is possible that low density levels, below the detection threshold of the CUFES, may have caused "methodological" false absence (Lobo et al., 2010) and negatively impacted the model's reliability. In contrast, Gaussian models performed well for all four species. Once the models were combined into delta models, the measured performances remained very satisfactory (based on Adj- $\mathrm{R}^{2}$ and Spearman's rank correlations), although the delta models were found to predict significantly lower values than those actually observed. By construction, delta models combining presence-absence and central tendency levels of density can never reproduce the highest densities observed (Loots et al., 2010 and 2011).

Nevertheless, these results highlighted that the patterns of fish egg distribution was very influenced by environmental conditions. Although these models presented high Adj- $\mathrm{R}^{2}$, environment alone is not believed to be the sole driver of spawning ground choice. Local egg density may also be influenced by other factors relative to characteristics intrinsic to the population (Planque et al., 2011), such as spawners' density or demographic structure (Loots et al. 2010a; Loots et al., 2011). Moreover, spawning is known to interact with biotic controls, such as predation, competition, food availability, parasites and disease. Future studies on modelling the spawning grounds using egg distribution should account for other factors, such as demographic or biotic controls. 
The methodological approach taken here was designed to limit the effect of autocorrelation by building models on spatially independent subsets of the data, and select these models based on their predictive power using an independent dataset. The low, and often non-significant, levels of spatial autocorrelation left in the models' residuals confirmed the correctness of the approach. The absence of clear pattern in the model standardised residual maps was further evidence of this. In the case of dab egg distribution, however, significant autocorrelation could still be detected, which indicated that spatial dependence could occur at larger scale than the sampling grid resolution $(0.6 \mathrm{dd})$. Using a coarser resolution would have resulted in even smaller calibration datasets and an important loss of information. For this species, the use of detrending technics (Legendre and Legendre, 2012), or a model with a contagion component (Dormann et al., 2007), may be solutions. However, such methods may also overcompensate for spatial autocorrelation (Segurado et al., 2006; Khun, 2007; Kissling and Carl, 2008), and fail to disentangle the induced spatial dependence from the autogenic autocorrelation.

\subsection{Delineating spawning habitats using environmental variables}

Eggs of the four species considered in this study are pelagic and drift passively; it is hence not straightforward to define their habitat (Fuiman, 2002). Abiotic factors such as sediment types or currents are, however, expected to affect habitat use by demersal spawners. Temperature is an important variable since it affects the rate of development and the mortality of eggs, while salinity influences the buoyancy of eggs (Gibson, 2005). Finally, chlorophyll $a$ concentration is a proxy for primary production. The present study revealed a clear link between environmental conditions and the spatio-temporal distribution of spawning grounds. The binomial and Gaussian models separately highlighted which variables conditioned egg presence and density levels, confirming that different ecological mechanisms were at play behind observed presence-absence and density levels, thereby justifying the two steps modelling approach. All the tested environmental variables were retained in the final delta models. This indicated that these variables were good proxies of the factors at play in the determination of these species' spawning habitats.

During the study period, chlorophyll $a$ concentration was relatively low, with a four-year mean of $0.51 \mu \mathrm{g} .1^{-1}$, with highest concentrations mainly found along the Belgium and Dutch coasts, and over the Dogger Bank. Egg distributions appeared to be negatively linked to chlorophyll $a$ concentration. However, only very high chlorophyll $a$ levels have detrimental 
effect on egg density and only very coastal areas may truly present lower habitat suitability. In the Gulf of Tunis, where chlorophyll $a$ concentrations are much lower than those observed in the southern North Sea, it was not directly correlated with the spatial distribution of fish eggs (Zarrad et al., 2003).

For all four species, low to intermediate depths were found to favour both egg presence and densities. Spawning grounds are often found at shallow depths in the southern North Sea (Gibson, 2005) and depth is known to be a major element influencing fish egg distribution in other areas (e.g. Zarrad et al., 2003). For instance, dab spawns in coastal waters, on the Dogger Bank and in the central North Sea, at depths between 20 and $40 \mathrm{~m}$ (van der Land, 1991; Rijnsdorp et al., 1992). Similarly, high concentrations of plaice eggs are typically found in shallow areas, shallower than $50 \mathrm{~m}$ (Harding et al., 1978).

The annual habitat maps resulting from the specific environmental configuration of the study area highlighted that higher salinities often favoured high egg densities. The separate effects of salinity on egg presence or density could, however, be quite variable amongst species. This revealed that the effect of salinity in the delta model may have been masked by other, more constraining, variables, such as depth. Although little is known about the salinity influence on spawning habitat, Laurence and Rogers (1976) found that cod eggs could develop within a salinity range of 28-36 PSU, and Riley and Parnell, (1984) reported that cod spawned in waters of salinity ranging between 34 and 35 PSU. Mean salinity in the study area was 34.9 PSU, decreasing to 30.2 PSU along the Belgium, Dutch and Danish coasts, due to fresh water flowing into the North Sea from numerous river estuaries (Meuse, Rhine, Escaut, Elbe and sometimes the Thames River). Therefore, these relatively low salinity areas may not always be suitable for cod, and possibly the three other spawning species.

Temperature was found to be negatively correlated to egg density in almost all the models developed here, regardless of the species, although this environmental variable may increase the presence probability of plaice and dab eggs. Temperature is known to influence the time and duration of the spawning season (Gibson, 2005), along with incubation time and egg survival (van der Land, 1991; Bunn et al., 2000). During the surveys, warmest temperatures were measured close to the Scottish coast $\left(9^{\circ} \mathrm{C}\right)$, whilst colder waters $\left(4^{\circ} \mathrm{C}\right)$ occurred along the German and Danish coasts. This temperature range was not truly limiting for the studied species: plaice eggs have a survival range between 2 and $8^{\circ} \mathrm{C}$ (Harding et al. 1978), whiting 
eggs survive well at temperatures between $6^{\circ} \mathrm{C}$ and $9^{\circ} \mathrm{C}$ (Loots, 2010a) and cod eggs between 2 and $10^{\circ} \mathrm{C}$ (Laurence and Rogers, 1976, Righton et al., 2010). The shape of the relationships modelled in the present study reflected these survival ranges, with plaice, cod and dab spawning habitat being more restricted to the coolest waters $\left(<7^{\circ} \mathrm{C}\right)$, although plaice could also tolerate relatively warmer temperatures, and whiting having a broader temperature preference.

Overall, these results confirmed that spawning areas were mainly distributed near frontal areas, which are located between low salinity coastal waters and shelf waters, in agreement with Munk et al. (2002 and 2009). Indeed, the hyaline front located in the eastern part of the North Sea, in the shallow Region Of Freshwater Influence (ROFI), mainly in the Dogger Bank and German Bight areas, represents areas of low salinity, resulting from freshwater inputs from rivers and the shelf sea regime of small salinity gradients. These areas are known to be extremely productive habitats that support relatively dense aggregations of early stage fish.

In the study area, bedstress was most intense in the southern part in the Dover Strait and adjacent areas. Most species appeared to prefer low to intermediate bedstress levels, though whiting was clearly more tolerant to higher bedstress levels. Plaice and dab spawning adults have already been shown to prefer areas with weak to intermediate bedstress (Loots et al., 2010a, Martin et al., 2010). Weak bedstress associated to fine sediment types may be representative of less disturbed areas in term of currents, which may favour spawning. In the present study cod, dab and plaice eggs were found over mud and sand, while whiting eggs could be found on a wide variety of coarse sediment types. Gibson (2005) showed that flatfish populations occur in areas where there are large areas of shallow sandy or muddy-sand sediments, which are common in the North Sea. Although many species do not feed during spawning (Rijnsdorp, 1989; Fuiman and Werner, 2002), seascape provided by substrates and associated benthic fauna might still remain fundamental for spawning location selection by bentho-demersal species. This may explain why seabed sediment type was significant in almost all models.

\subsection{Fluctuation in spawning grounds location}

Although only based on four years of survey data (from 2006 to 2009), the present study attempted to delineate boundaries between recurrent and occasional spawning sites. In a 
preliminary study of the CUFES' efficiency, species egg composition and density found in CUFES were compared to vertical egg tow samples over the same area and at the same period (Lelièvre et al., 2012a). Some species egg such as flounder were better represented in CUFES possibly resulting from positive egg buoyancy or a near surface spawning behaviour. On the other hand, in low wind speeds, shallow water and weak bedstress conditions, the water column mixing may become insufficient for CUFES to accurately depict egg density over the whole water column. Change in egg catchability in the sub-surface layer may alter CUFES efficiency and, as a result, wind speed variability between the different years of study may generate change in the observed egg distribution. However, this former study also showed that differences in sampling efficiency between the two studied gears were not large enough to unduly influence distribution maps and we do not believe this effect to be significant in our present results. Hence, the methodology presented here provides a practical approach for measuring the temporal variability associated with fish egg distributions. The methodology used in Bellier et al. (2007) was modified to account for the fact that high variability levels may reflect both large abundance values and high inter-annual variability. Here, the rescaling of each annual map between 0 and 1 enabled to disentangle both sources of variability, and to eliminate annual change in absolute density levels, so as to focus only on the spatial variability; this resulted in an improved delineation of recurrent areas.

Dab eggs were widely distributed throughout the study area, mainly offshore (Gibson, 2005), over the Dogger Bank, which represented a recurrent spawning area and corresponded to large adults distribution patches (Martin et al., 2010). However, aggregations of dab eggs could also be found near the Dutch, German and Danish coasts. These patterns were partly confirmed by previous studies that showed that dab spawning occurs throughout the southeastern part of the North Sea, with offshore egg concentrations in the German Bight and on the Dogger Bank (Bohl, 1957; van der Land, 1991; Rijnsdorp et al, 1992). Although Harding and Nichols (1987) also found some egg concentrations north-east of Flamborough Head, this was not the case in the present study, maybe due to the difference in study period (end of January to end of May for Harding and Nichols' study).

Plaice spawning grounds were mainly distributed offshore from the Dutch, German and Danish coasts (Gibson, 2005). Harding et al. (1978) reported that plaice spawning occurs over most of the offshore and deeper parts of the southern North Sea, which corresponded in the present study to a recurrent spawning area. However and in contrast to Hessen and Rijnsdorp 
(1989) and Fox et al. (2005b), lower egg density was also found in the eastern English Channel and in the southern Bight. The eastern English Channel was categorised as a rare spawning area, with low egg density and high inter-annual variability in January-February. This may be due to a northward extension of plaice spawning ground, or to the timing of the survey which may not coincide with its spawning season in the English Channel.

In the present study, cod eggs were mainly distributed near the Dutch, German and Danish coasts. This distribution was similar to historical patterns where eggs were the most abundant around the southern and eastern edge of the Dogger Bank and in the German Bight (Brander, 1994; Fox et al., 2005; ICES, 2005b; Fox et al., 2008; ICES, 2010). Although spawning aggregations may be found offshore all over the North Sea, a survey in spring 2004, showed that the most important concentration was found in a restricted area to the northwest of the Dogger Bank (Fox et al., 2005b), and that egg density in the southern North Sea was much lower than in the past (Daan et al., 1978). In the present study, cod spawning grounds seemed to be recurrent in the southern North Sea, and occasional in the eastern English Channel, as for whiting.

High concentrations of whiting eggs were mainly located in the eastern English Channel, in the southern Bight and south of the Dogger Bank. These areas were categorised as occasional spawning grounds, due to high inter-annual variability. These results are in agreement with historical spawning areas described by Coull et al. (1998), Gibb et al. (2004) and ICES (2010).

Results presented here highlighted a strong fidelity of adults for their spawning grounds. This has already been reported for plaice (ICES 2005a and b; ICES 2007), based on historical data (e.g. Simpson, 1959). Moreover, tagging experiments have demonstrated strong spawning site fidelity behaviour by plaice in the North Sea (de Veen, 1978, Hunter et al., 2003), around Iceland (Solmundsson et al., 2005), and in Scottish waters (Wright et al., 2006). Studies of spawning distributions of abundant North Sea fish (e.g. for cod: Brander, 1994; Daan, 1981; Raitt, 1967, e.g. for plaice: Simpson, 1959) generally suggest a persistent use of spawning areas over time (Heath et al., 1994; Hunter et al., 2003; Gibb et al., 2004), and this even though past population sizes may have been much larger than they currently are (Daan, 1978; Brander, 1994; Fox et al., 2008). Fox et al. (2000) suggested that spawning locations of cod and plaice have probably not changed much over the last 30 years. Cod, whiting and plaice 
spawning stock biomass were at their historical low in 2006 and showed the first signs of recovery in the following years (ICES, 2013). The present study therefore explores their spawning grounds' distribution in a period of particularly intense contraction of spawners' abundance. In contrast, dab landings were above average over all the study period (ICES, 2013). Moreover, Loots et al. (2010a and b) and Loots et al. (2011) showed that spawning adults of plaice and whiting had a strong geographical attachment for their spawning grounds, which suggests a homing mechanism (Papi, 1992). Spawning site fidelity may result from an adaptative strategy to place progeny within suitable environment and allow recruitment success (Peck et al., 2009, Hunter et al., 2003). The presence of predictable transport trajectories (such as tidal streams or dominant wind direction), allowing passive transport to nursery grounds, is believed to be the main driving factor explaining geographically stable spawning site selection (Cushing, 1990, Wennhage and Pihl, 2001).

The occasional spawning areas highlighted in the present study may play an important role in population renewal. For instance, these areas may actually display higher egg densities before and/or after the surveys occurred, i.e. January-February. At that time of year, not all studied species happen to be in the same spawning condition. The studied period corresponded to the peak of spawning for both plaice (Harding et al., 1978), which spawn from December to April (Munk and Nielsen, 2005) and cod (Heessen and Rijnsdorp, 1989), which has peak of spawning from the last week of January to mid-February (in the study area). However, and although their eggs were very abundant, dab and whiting's spawning seasons were just starting at the time of the surveys. Dab is believed to spawn from February to April (HtunHan, 1978), and from February to June with a peak in April for whiting (Gibb et al., 2004). Similarly, common sole spawning period is understood to only begin in March (Munk and Nielsen, 2005); as some sole eggs were identified during the survey, it may be that some individuals are able to start spawning well in advance of the bulk of their population.

For dab, plaice and cod, occasional areas were southward coastal extension of recurrent areas. These areas, corresponding to the main river plumes, may be too cold, too desalted or too rich in nutrient to always serve as suitable spawning grounds for them. Moreover, in these areas spawning may be influenced by water quality (both eutrophication and pollution) and exposure to pollutants may generate chemical changes in the eggs, causing deformities or reduced viability (Gibson, 2005). In the case of whiting, occasional areas formed the bulk of 
its spawning grounds and covered the entire southern Bight, clearly indicating that the survey data did not capture the peak of spawning and the core spawning grounds of this species.

\subsection{Conservation of spawning areas}

By 2020, at least 10 per cent of coastal and marine areas should be conserved through systems of protected areas, according to Aichi Biodiversity Target 11 (Conference of the Parties to the Convention on Biological Diversity, 2010). The establishment of Marine Protected Areas (MPAs) is one way to achieve this objective, along with being an important tool for fisheries management (Côté and Finney, 2006). Several studies have shown that MPAs can achieve conservation and fisheries management objectives by increasing biodiversity, restoring population structure and the dynamics of stocks and by facilitating the establishment of stable and productive ecosystems (Araújo and Williams, 2000; Fisher and Frank, 2002; Gell and Roberts, 2003; Roberts et al. 2005; Kremen et al., 2008; Kraus et al. 2009). When spawning aggregations are the main target of commercial fisheries, some MPAs may be designed to specifically protect the corresponding areas. They are generally positioned on spawning or larval settlement areas, which requires information on fish egg aggregation and transport processes of larvae (Christensen et al. 2009). Thus, knowledge on spawning ground locations can directly contribute to the sustainable management of fisheries' resources, and managers may decide to prohibit the use of a given area to protect spawning and hence help maintaining a productive fishery. Other technical measures include limiting trawl mesh size to protect adults and ensure that they have the opportunity to reproduce at least once (Fuiman and Werner, 2002). Spawning and nursery grounds may also be closed to other human activities that can alter the physical or chemical properties of the habitat, and hence their suitability. One of the reasons for monitoring and delineating spawning areas over time is because they are flexible in time (which was confirmed in this study) but this is seldom taken into account in management. The use of recurrence maps, defining which areas are repeatedly used over time may inform managers on the location of the most stable spawning grounds.

The multispecific winter spawning habitat map highlighted areas that were the most suitable for the four species considered: these included the Dover Strait, a large area extending from the Dutch, German and Danish coasts to the Dogger Bank and the Flamborough Head, which are also main nursery areas (Harding and Nichols, 1987). These areas are very partially protected by existing Natura 2000 areas, as in the German Bight, and planned marine parks (e.g. that of the "three estuaries" in the eastern English Channel). This map is well adapted to 
a precautionary principle approach, as it reflects all potentially suitable areas to the four studied species spawning although it might be difficult to implement the protection of such large areas. On the other hand, the spawning recurrence frequency map highlighted a different area of smaller spatial extent, and located offshore in the southeastern North Sea. This map showed recurrent spawning areas, exhibiting a stronger temporal stability in both their characteristics and use by the four species, which may be easier in practical terms to protect, especially as they are located away from intensive coastal human activities. However, intensive fishing effort takes place in this area and protection of the spawning grounds against fisheries may be difficult to put into place (Coull et al., 1998, Jennings et al., 1999, Greenstreet et al., 2007).

\section{Conclusion}

Ichthyoplankton surveys are a powerful tool to better understand spawning areas (Fox et al., 2005a), and the present study has provided high-resolution maps of spawning habitats, and new insights on their utilisation by spawners. Environment-driven recurrent spawning grounds were well defined and coherent with other studies, and large occasional spawning areas were also highlighted. If a policy ensuring sustainable use of marine resources is to be implemented in the southern North Sea, the knowledge on the location and functionality of spawning habitats is a critical step for selecting a combination of sites with good spatial and ecological coherence.

\section{Acknowledgements}

This work was jointly funded by the Région Nord Pas-de-Calais and IFREMER. We also acknowledge financial support from the European Union through its European Regional Development Fund (Interreg $3 \mathrm{a}$ and $4 \mathrm{a}$ ) as part of the ISADO and CHARM projects. The authors would like to express their sincere thanks to the scientific staff and crew of $R V$ Thalassa for their support for the sampling at sea. CSM carried out some of the work with funding from the European Union (MC FP7-PEOPLE-IEF-2008, grant 235791).

\section{References}

Adlandsvik, B., Coombs, S., Sundby, S. and Temple, G., 2001. Buoyancy and vertical distribution of eggs and larvae of blue whiting (Micromesistius poutassou): observations and modeling. Fish. Res. 50, 59-72.

Aldridge, J.N. and Davies, A.M., 1993. A high-resolution three-dimensional hydrodynamic tidal model of the eastern Irish Sea. J. Phys. Oceanogr., 23, 207-224. 
Akaike, H., 1974. A new look at the statistical model identification. IEEE Transactions on Automatic Control, 19, 716-723.

Anonymous, 2002. Bergen Declaration. Fifth International Conference on the Protection of the North Sea, 20-21

March 2002 Bergen, Norway

Araújo, M.B. and Williams, P.H., 2000. Selecting areas for species persistence using occurrence data. Biol. Conserv. 96, 331-345.

Bakun, A., 1996. Pattern in the ocean: Ocean processes and marine population dynamics, 341p.

Barry, S.C. and Welsh, A.H., 2002. Generalized additive modelling and zero inflated count data. Ecol. Model., $157,179-188$.

Begg, G.A. and Marteinsdottir, G., 2002. Environmental and stock effects on spawning origins and recruitment of cod Gadus morhua. Mar. Ecol. Prog. Ser., 229, 245-262.

Benaka, A., 1999. Fish habitat: essential fish habitat and rehabilitation. American Fisheries Society, 400 pp.

Bellier, E., Planque, B. and Petitgas, P., 2007. Historical fluctuations in spawning location of anchovy (Engraulis encrasicolus) and (Sardina pilchardus) in the Bay of Biscay during 1967-73 and 2000-2004. Fish. Oceanogr., 16, 1-15.

Bivand, R., with contributions by Altman, M., Anselin, L., et al., 2012. spdep: Spatial dependence: weighting schemes, statistics and models. R package version 0.5-51. http://CRAN.R-project.org/packages=spdep.

Bocard, D., Gillet, F. and Legendre, P., 2011. Numerical ecology with R.

Bohl, H., 1957. Die Biologie der Kliesche (Limanda limanda L.) in der Nordsee. Ber. dt. wiss. Kommn Meeresforsch, 15, 1-57.

Brander, K.M., 1994. The Location and Timing of Cod Spawning Around the British-Isles. ICES J. Mar. Sci., 51, 71-89.

Bunn, N., Fox, C. and Webb, T., 2000. A litterature review of studies on fish egg mortality: implication for the estimation of spawning stock biomass by the annual egg production method, Science series Technical Report 111, 37 pp.

Burnham, K.P. and Anderson, D.R., 2002. Model selection and multimodel inference. A practical informationtheoritic approach. Springer-Verlag, USA. 488 pp.

Canty, A. and Ripley, B., 2012. boot: Bootstrap R (S-Plus) Functions. R package version 1.3-4.

Checkley, D.M., Ortner, P.B., Settle, L.R. and Cummings, S.R., 1997. A continuous, underway fish egg sampler. Fish. Oceanogr., 6, 58-73.

Christensen, A., Jensen, H. and Mosegaard, H., 2009. Spatially resolved fish population analysis for designing MPAs: influence on inside and neighbouring habitats. ICES Jour Mar Sci, 66, 56-63.

Conference of the Parties to the Convention on Biological Diversity, 2010. COP 10 Decision X/2, Strategic Plan for Biodiversity 2011-2020. Tenth meeting of the Conference of the Parties to the Convention on Biological Diversity, 18 - 29 October 2010 - Nagoya, Aichi Prefecture, Japan.

Conway, D.V.P., Coombs, S.H. and Smith, C., 1997. Vertical distribution of fish egg and larvae in the Irish Sea and southern North Sea. ICES J. Mar. Sci., 54, 136-147.

Côté, F. et Finney, J., 2006. Marine protected areas: an essential ellement of the fisheries management toolbox, Bibliothèque du parlement, 16 pp. 
Coull, K.A., Johnstone, R. and Rogers, S.I., 1998. Fisheries sensitivity maps in British waters, published and distributed by UKOOA Ltd. 63pp.

Cushing, D.H., 1990. Hydrographic containment of a spawning group of plaice in the Southern Bight of the North Sea. Mar. Ecol. Prog. Ser. 58:287-297.

Daan, N., 1978. Changes in cod stocks and cod fisheries in the North Sea. Rapports et Procès-verbaux des Réunions du Conseil International pour l'Exploration de la Mer 172, 39-57.

Daan, N., 1981. Comparison of estimates of egg production of the Southern Bight cod stock from plankton surveys and market statistics. 178, 242-243. Rapports et Procés-Verbaux des Réunions du Conseil International pour l'Exploration de la Mer.

Davison, A.C. and Hinkley, D.Y., 1997. Bootstrap methods and their applications. Cambridge University Press. Cambridge ISBN 0-521-57391-2.

de Veen, J.F., 1978. On selective tidal transport in the migration of North Sea plaice (Pleuronectes platessa) and other flatfish species. Neth. J. Sea Res., 12, 115-147.

Diniz-Filho, J.A.F., Bini, L.M. and Hawkins, B.A., 2003. Spatial autocorrelation and red herrings in geographical ecology. Global Ecol. Biogeogr., 12, 53-64.

Dormann, C.F., 2007. Effects of incorporating spatial autocorrelation into the analysis of species distribution data. Global Ecol. Biogeogr., 16, 129-138.

Dormann, C.F., McPherson, J.M., et al., 2007. Methods to account for spatial autocorrelation in the analysis of species distributional data: a review. Ecography, 30, 609-628.

ESRI ArcGis, Desktop Geographic Information System, ArcView Licence, ArcMap 9.2 with ArcGis Spatial Analyst extension. Copyright 1999-2006 ESRI Environmental Systems Research Institute Inc.

Fisher, J. and Frank, K., 2002. Changes in finfish community structure associated with an offshore fishery closed area on the Scotian Shelf, Mar. Ecol. Prog. Ser., 240, 249-264.

Fox, C.J., O'Brien, C.M., Dickey-Collas, M. and Nash, R.D.M., 2000. Patterns in the spawning of cod (Gadus morhua L.), sole (Solea solea L.) and plaice (Pleuronectes platessa L.) in the Irish Sea as determined by generalized additive modelling. Fish. Oceanogr., 9, 33-49.

Fox, C., Taylor, I., Pereyra, R. et al., 2005a. TaqMan DNA technology confirms likely overestimation of cod (Gadus morhua L.) egg abundance in the Irish Sea: implication for the assessment of the cod stock and mapping of spawning areas using egg-based methods. Mol. Ecol. 14, 897-884.

Fox, C., Taylor, M., Dickey-Collas, M., Van Damme, C.J.G., Bolle, L., Daan, N., Rohlf, N., Kraus, G., Munk, P., Fossum, P. and Bailey, N., 2005b. Initial results from the 2004 ichthyoplankton survey of the North Sea. ICES Annual Conference Meeting 2005/AA:04.

Fox, C.J., Taylor, M., Dickey-Collas, M., Fossum, P., Kraus, G., Rohlf, N., Munk, P., van Damme, C.J.G., Bolle, L.J., Maxwell, D.L., Wright, P.J., 2008. Mapping the spawning grounds of North Sea cod (Gadus morhua) by direct and indirect means. P. Roy. Soc. B-Biol. Sci., 275, 1543-1548.

Fox, J. and Weisberg, S., 2011. An R Companion to Applied Regression, Second Edition, Sage.

Freeman, E.A. and Moisen, G., 2008. PresenceAbsence: An R Package for Presence-Absence Model Analysis. J. Stat. softw., 23 (11), 1-31. http://www.jstatsoft.org/v23/ill.

Fuiman, L.A. and Werner, R.G., 2002. Fishery Science, The unique contribution of early life stages. Blackwell Publishing, $325 \mathrm{pp}$. 
GenStat Release 7.1, Copyright, 2004. Lawes Agricultural Trust (Rothamsted Experimental Station). Payne RW, Hardings SA, Maurray DA, Soutar DM, Baird DB, Welham SJ, Kane AF, Gilmour AR, Thompson R, Webster R and Tunnicliffe Wilson. G. VSN International, Wilkinson House, Jordan Hill Road, Oxford, UK.

Gell, F.R. and Roberts, C.M., 2003. Benefits beyond boundaries: the fishery effects of marine reserves, Trends Ecol Evol, 18, 448-455.

Gibb, F.M., Wright, P.J., Gibb, I.M. and O’Sullivan, M., 2004. Haddock and whiting spawning areas in the North Sea and Scottish west coast. Fishery Research Services, Internal Report, 11/04, 11pp.

Gibson, R.N., 2005. Flatfishes Biology and Exploitations. Fish and aquatic resources Series 9. Blackwell science, $390 \mathrm{pp}$.

Greenstreet, S. P. R., Robinson, L. A., Piet, G. J., Craeymeersch, J., Callaway, R., Reiss, H., Ehrich, S., Kröncke, I., Fraser, H., Lancaster, J., Jorgensen, L., Goffin, A., 2007. The ecological disturbance caused by fishing in the North Sea; p. 169. FRS Collaborative Report, 04/07.Guisan, A. and Zimmermann, N.E., 2000. Predictive habitat distribution models in ecology. Ecol. Mod., 135, 147-186.

Guisan, A., Lehmann, A., Ferrier, S., 2006. Making better biogeographical predictions of species distributions. J. Appl. Ecol., 43, 386-392.

Harding, D., Nichols, J.H. and Tungate, D.S., 1978. The spawning of plaice (Pleuronectes platessa L.) in the southern North Sea and English Channel. Rapports et Procès-Verbaux des Réunions du Conseil International pour l'Exploration de la Mer, 172, 102-113.

Harding, D. and Nichols, J.H., 1987. Plankton surveys off the north-east coast of England in 1976: an introductory report and summary of the results. Fisheries Research, Technical Report 86, MAFF Direct Fisheries Research, Lowestoft, 56 pp.

Heath, M., Rankine, P. and Cargill, L., 1994. Distribution of Cod and Haddock Eggs in the North Sea in 1992 in Relation to Oceanographic Features and Compared with Distributions in 1952-1957 (Abstract). Cod and Climate Change - Proceedings of A Symposium, 198, 438-439.

Hessen, H.J.L. and Rijnsdorp, A.D., 1989. Investigations on egg production and mortality of cod (Gadus morhua L.) and plaice (Pleuronectes platessa L.) in the southern and eastern North Sea in 1987 and 1988. Rapports et Procès-Verbaux des Réunions du Conseil International pour l'Exploration de la Mer, 191, $15-20$.

Hunter, E., Metcalfe, J.D. and Reynolds, J.D., 2003. Migration route and spawning area fidelity by North Sea plaice. P. Roy. Soc. B-Biol.Sci., 270, 2097-2103.

Htun-Han, M., 1978. The reproductive biology of the dab Limanda limanda (L.) in the North Sea: Seasonal changes in the ovary. J. Fish Biol., 13, 351-359.

ICES, 2004. Manual for the international bottom trawl surveys, rev. VII. International Bottom Trawl Survey Working Group, $\quad$ ICES, $\quad$ Copenhagen. $\quad 51 \quad$ pp. http://www.ices.dk/datacentre/datras/NSIBTSmanualRevVIIdraft.pdf.

ICES, 2005a. Report of the Planning Group on North Sea Cod and Plaice Egg Surveys in the North Sea (PGEGGS), 10-12 May 2005, Lowestoft, UK. ICES Annual Conference Meeting 2005/G:11, 85 pp.

ICES, 2005b. Spawning and life history information for North Atlantic cod stocks. ICES Cooperative Research Report 247, 152 pp. 
ICES, 2007. Results of the spring 2004 North Sea ichthyoplankton surveys. ICES Cooperative Research 285, 59 pp.

ICES, 2009. Report of the Planning Group on North Sea Cod and Plaice Egg Surveys (PGEGGS), 2-3 December 2008, IMARES, IJmuiden, the Netherlands. CM2008/2/LRC01. 36 pp.

ICES, 2010. Report of the Working Groups on North Sea Cod and Plaice Egg Surveys in he North Sea (WGEGGS), 9-11 November 2010, ICES Headquarters, Copenhagen. ICES Annual Conference Meeting 2010/SSGESST: 23, 29pp.

ICES. 2013. Report of the ICES Advisory Committee 2013. ICES Advice, 2013. Book 6.

Jennings, S., Greenstreet, Simon. P. R. and Reynolds, John. D., 1999. Structural change in an exploited fish community: a consequence of differential fishing effects on species with contrasting life histories. Journal of Animal Ecology, 68: 617-627Jiménez-Valverde, A. and Lobo, J.M., 2007. Threshold criteria for conversion of probability of species presence to either-or presence-absence. Acta Oecologica, 31, 361-369.

Kraus, G., Pelletier, D., Dubreuil, J., Mollmann, C., Hinrichsen, H., Bastardie, F., Vermard, Y., Mahevas, S., 2009. A model-based evaluation of Marine Protected Areas: The example of eastern Baltic cod (Gadus morhua callarias L.) ICES J Mar Sci, 109-121.

Kissling, W.D. and Carl, G., 2008. Spatial autocorrelation and the selection of simultaneous autoregressive models. Global Ecol. Biogeogr., 17, 59-71.

Kremen, et al., 2008. Aligning Conservation Priorities Across Taxa in Madagascar with High-Resolution Planning Tools. Science, 320.

Kühn, I., 2007. Incorporating spatial autocorrelation may invert observed patterns. Diversity and Distributions, 66-69.

Lauria, V., Vaz S., Martin, C.S., Mackinson, S., Carpentier, A., 2011. What influences European plaice (Pleuronectes platessa) distribution in the eastern English Channel? Using habitat modelling and GIS to predict habitat utilization. ICES J. Mar. Sci., 68, 1500-1510.

Laurence, G.C. and Rogers, C.A., 1976. Effects of Temperature and Salinity on Comparative Embryo Development and Mortality of Atlantic Cod (Gadus-Morhua-L) and Haddock (MelanogrammusAeglefinus L). J. Cons. Int. Explor. Mer, 36(3), 220-228.

Larsonneur, C., Bouysse, P. and Auffret, J.P., 1982. The superficial sediments of the English Channel and its Western Approaches. Sedimentology, 29: 851-864.

Legendre, P. and Legendre, L., 2012. Numerical ecology, $3^{\text {rd }}$ edn. Elsevier, Amsterdam, 990 pp.

Lelièvre, S., Verrez-Bagnis, V., Jérôme, M. and Vaz, S., 2010a. PCR-RFLP analyses of formalin-fixed fish eggs for the mapping of spawning areas in the Eastern Channel and Southern North Sea, J. Plankton Res.; 32 (11), 1527-1539.

Lelièvre, S., 2010b. Identification et caractérisation des frayères hivernales en Manche Orientale et la partie sud de la mer du Nord. PhD thesis, Université de nantes. http://archimer.ifremer.fr/doc/00043/15398/.

Lelièvre, S., Fox, C. and Vaz, S., 2012a. The effectiveness of the Continuous Underway Fish Egg Sampler (CUFES) compared with standard vertical plankton haul for demersal species of the southern North Sea. Fish. Oceanogr., doi:10.1111/j.1365-2419.2012.00613.x 
Lelièvre, S., Jérôme, M., Maes, G., Vaz S., Sachidhanandam, C. and Verrez-Bagnis, V., 2012b. Molecular validation and comparative mapping of morphologically identified eggs of dab (Limanda limanda), flounder, (Platichtys flesus) and Trisopterus sp. from the Eastern English Channel and southern North Sea. Mar. Ecol. Prog. Series, 445, 161-172.

Le pape, O., Chauvet, F., Mahevas, S., Lazure, P., Guerault, D. and Desaunay, Y., 2003. Quantitative description of habitat suitability for the juvenile common sole (Solea solea) in the Bay of Biscay (France) and the contribution of different habitats to adult population. J. Sea Res., 50, 139-149.

Lo, N.C.H., Hunter, J.R. and Charter, R., 2001. Use of a continuous egg sampler for ichtyoplancton surveys: application to the estimation of daily egg production of Pacific sardine (Sardinops sagax) off California. Fish. B-NOAA, 99, 554-571.

Lobo, J.M., Jiménez-Valverde, A. and Hortal, J., 2010. The uncertain nature of absences and their importance in species distribution modelling. Ecography, 33, 103-114.

Loots, C., Vaz, S., Planque, B. and Koubbi, P., 2010a. What controls the spatial distribution of North Sea plaice spawning population? Confronting ecological hypotheses through a model selection framework. ICES J. Mar. Sci., 67, 244-257.

Loots, C., Vaz, S., Koubbi, P., Planque, B., Coppin, F. and Vérin, Y., 2010b. Inter-annual variability of North Sea plaice spawning habitat. J. Sea Res., 64, 427-435.

Loots, C., Vaz, S., Planque, B. and Koubbi, P., 2011. Understanding what controls the spawning distribution of North Sea whiting (Merlangius merlangus) using a multimodel approach. Fish. Oceanogr., 20, 18-31.

Maier-Reimer, E. (1977). Residual circulation in the North Sea due to the M2-tide and mean annual wind stress. Deutsche Hydrografische Zeitschrift, 30(3), 69-80.

Mastail, M. and Battaglia, A., 1978. Amélioration de la conservation des pigments du zooplancton. Cons. Inter. Explor. Mer (CIEM), Comité de l'Océanographie biologique, L : 20.

Martin, C.S., Carpentier, A., Vaz, S., Coppin, F., Curet, L., 22 co-authors, 2009. The Channel Habitat Atlas for marine Resource Management (CHARM): an aid for planning and decision-making in an area under strong anthropogenic pressure. Aquat. Living Resour., 22, 499-508.

Martin, C.S., Vaz, S., Ellis, J.R., Lauria, V., Coppin, F., Carpentier, A., 2012. Modelled distributions of ten demersal elasmobranchs of the eastern English Channel in relation to the environment. J. Exp. Mar. Biol. Ecol., 418-419, 91-103.

Martin, C.S., Vaz, S., Koubbi, P., Meaden, G.J., Engelhard, G.H., Lauria, V., Gardel, L., Coppin, F., Delavenne, J., Dupuis, L., Ernande, B., Foveau, A., Lelièvre, S., Morin, J., Warembourg, C. and Carpentier, A., 2010. A digital atlas to link ontogenic shifts in fish spatial distribution to the environment of the eastern English Channel. Dab, Limanda limanda as a case-study. Cybium, 34, 59-71.

McCullagh, P. and Nelder, J.A., 1989. Generalized linear models, 2nd Ed. London, England: Chapman \& Hall/CRC, $511 \mathrm{pp}$.

Munk, P., Larsson, P.O., Danielssen, D.S. and Moksness, E., 1999. Variability in frontal zone formation and distribution of gadoid fish larvae at the shelf break in the northeastern North Sea. Mar. Ecol. Prog. Ser., 177, 221-233

Munk, P., Wright, P.J. and Phil, N.J., 2002. Distribution of the early larval stages of cod, plaice and lesser sandeel across haline fronts in the North Sea. Estuar. Coast. Shelf Sci., 55, 139-149. 
Munk, P. and Nielsen, J., 2005. Eggs and Larvae of North Sea Fishes. Biofolia, 215 pp.

Munk, P., Fox, C.J., Bolle, L.J., van Damme, C.J.G., Fossum, P. and Kraus, G., 2009. Spawning of North Sea fishes linked to hydrographic features. Fish. Oceanogr., 18, 458-469.

Papi, F., 1992. Animal homing. Chapman and Hall, London, 390 pp.

Peck, M.A., KÜhn, W., Hinrichsen, H.H. and Pohlmann, T., 2009. Inter-annual and inter-specific differences in the drift of fish eggs and yolksac larvae in the North Sea: A biophysical modelling approach. Sci. Mar., 73S1, doi: 10.3989/scimar.2009.73s1023.

Pépin, P., Snelgrove, P.V.R. and Carter, K.P., 2005. Accuracy and precision of the continuous underway fish egg sampler (CUFES) and bongo nets: a comparison of three species of temperate fish. Fish. Oceanogr., 14, 432-447.

Petitgas, P., Magri, S. and Lazure, P., 2006. One-dimensional biophysical modelling of fish egg vertical distributions in shelf seas, Fish. Oceanogr., 15, 413-428.

Planque, B., Loots, C., Petitgas, P., Lindstrom, U. and Vaz, S., 2011. Understanding what controls the spatial distribution of fish populations using a multi-model approach. Fish. Oceanogr., 20, 1-17.

Planque, B., Bellier, E. and Lazure, P., 2004. otential spawning habitat of sardine (Sardinops pilchardus) and anchovy (Engraulis encrasicolus) in the Bay of Biscay. ICES Annual Conference Meeting Q:02, 17 pp.

R Development Core Team, 2005. R: A language and environment for statistical computing. R Foundation for Statistical Computing, Vienna, Austria. ISBN 3-900051-07-0, URL http://www.R-project.org.

Raitt, D.F.S., 1967. Cod spawning in Scottish waters. Preliminary investigations. ICES Annual Conference Meeting F:29, 3pp.

Research Application Program, 2012. NCAR - verification: Forecast verification utilities. R package version 1.35. http://CRAN.R-project.org/package = verification.

Righton, D. A., Andersen, K. H., Neat, F., Thorsteinsson, V., Steingrund, P., Svedäng, H., Michalsen, K., Hinrichsen, Hans-Harald, Bendall, V., Neuenfeldt, S., Wright, P., Jonsson, P., Huse, G., van der Kooij, J., Mosegaard, H., Hüssy, K. and Metcalfe, J., 2010. Thermal niche of Atlantic cod Gadus morhua: limits, tolerance and optima Marine Ecology Progress Series, 420 . pp. 1-13.Rijnsdorp, A.D., 1989. Maturation of male and female North Sea plaice (Pleuronectes platessa L.) J. Cons. Int. Explor. Mer, 46, $35-51$.

Rijnsdorp, A.D., Vethaak, A.D. and Van Leeuwe,n P.I., 1992. Population biology of dab Limanda limanda in the southeastern North Sea. Mar. Ecol. Prog. Ser., 91, 19-35.

Rijnsdorp, A.D., Peck, M.A., Engelhard, G.H., Möllmann, C. and Pinnegar, J.K., 2009. Resolving the effect of climate change on fish populations. ICES J. Mar. Sci., 66, 1570-1583.

Riley, J.D. and Parnell, W.D., 1984. The distribution of young cod In: The propagation of Cod, Gadus morhua L., Flodevigen rapportser.1.

Roberts, C.M., Hawkins, J.P., Gell, F.R., 2005. The role of marine reserves in achieving sustainable fisheries. In: Fisheries: a future?. Phil. Trans. R. Soc. B., 360, 123-132.

Russell, F.S., 1976. The egg and planktonic stages of British marine fishes. London, England, Academic Press Ltd, $524 \mathrm{pp}$.

Ryland, J. S. and Nichols, J. H., 1975. Effect of temperature on the embryonic development of the plaice, Pleuronectes platessa L. (Teleostei). J. Exp. Mar. Biol. Ecol., 18, 121-137. 
Sakamoto, Y., Ishiguro, M. and Kitagawa, G., 1986. Akaike Information Criterion Statistics. D. Reidel Publishing Company, Dordrecht/Tokyo.

Schlüter, M.M. and Jerosch, K., 2009. The digital atlas of the north sea: An overview about geo-information considering the sea floor and the bottom water column. MARGIS and METROL project. Alfred Wegener

Institute. http://www.awi.de/en/research/research_divisions/geosciences/marine_geochemistry/marine_gis/digital _atlas_of_the_north_sea/.

Schwarz, G., 1978. Estimating the dimension of a model. Ann. Stat., 6, 461-464.

Segurado, P., Araujo, M.B. and Kunin, W.E., 2006. Consequences of spatial autocorrelation for niche-based models, J. Appl. Ecol., 43, 433-444.

Simpson, A., 1959. The spawning of plaice (Pleuronectes platessa) in the North Sea. Fish. Invest. London Ser. 2 , $22,1-111$

Solmundsson, J., Palsson, J. and Karlsson, H., 2005. Fidelity of mature Icelandic plaice (Pleuronectes platessa) to spawning and feeding grounds. ICES J. Mar. Sci., 62, 189-200.

Stefánsson, G., 1996. Analysis of groundfish survey abundance data: combining the GLM and delta approaches, ICES J. Mar. Sci., 53, 577-588.

Stelzenmüller, V., Ellis, J.R., Rogers, S.I., 2010. Towards a spatially explicit risk assessment for marine management: assessing the vulnerability of fish to aggregate extraction. Biol. Conserv., 143 (2010), pp. 230-238.

Thompson, B. M. and Riley, J. D., 1981. Egg and larval development studies in the North Sea cod (Gadus morhua L.). Rapp. P-V. Réun. Cons. Int. Explor. Mer, 178, 553-559.van der Land, M., 1991. Distribution of flatfish eggs in the 1989 egg surveys in the southeastern North Sea, and mortality of plaice and sole eggs. Neth. J. Sea Res.; 27, 277-286.

van der Lingen, C.D., Checkley, D., Barange, M., Hutchings, L. And Osgood, K., 1998. Assessing the abundance and distribution of eggs of sardine Sardinops sagax, and round herring, Etrumeus whiteheadi, on the western Agulhas Bak, South Africa, using a continuous, underway fish egg sampler, Fish. Oceanogr., 7, 35-47.

Venables, W.N. and Ripley, B.D., 2002. Modern applied statistics with S Fourth Edition. Springer New York. ISBN 0-387-95457-0.

Wagenmakers, E.J. and Farrell, S., 2004. AIC model selection using Akaike weights. Psychon. B. Rev., 11, 192196.

Wennhage, H. and Pihl, I., 2001. Settlement patterns of newly settled plaice (Pleuronectes platessa) in a non-tidal Swedish fjord in relation to larval supply and benthic predators. Mar. Biol. 139:877-889.

Wilcoxon, F., 1945. Individual Comparisons by Ranking Methods. Biometrics Bull., 1, 80-83.

Wright, P.J., Galley, E., Gibb, I.M. and Neat, F.C., 2006. Fidelity of adult cod to spawning grounds in Scottish waters. Fish. Res., 77, 148-158.

Zarrad, R., El Abed, A., M'Rabet, R., Missaoui, H. and Romdhane, M.S., 2003. Distribution spatiale de l'ichtyoplancton en été et en automne et conditions environnementales dans le golfe de Tunis. Bull. Inst. Natn. Scien. Tech. Mer Salammbô, 30, 39-47.

Zuur, A.F., Ieno, E.N. and Smith, G.M., 2007. Analysing Ecological Data. Springer, New York. 


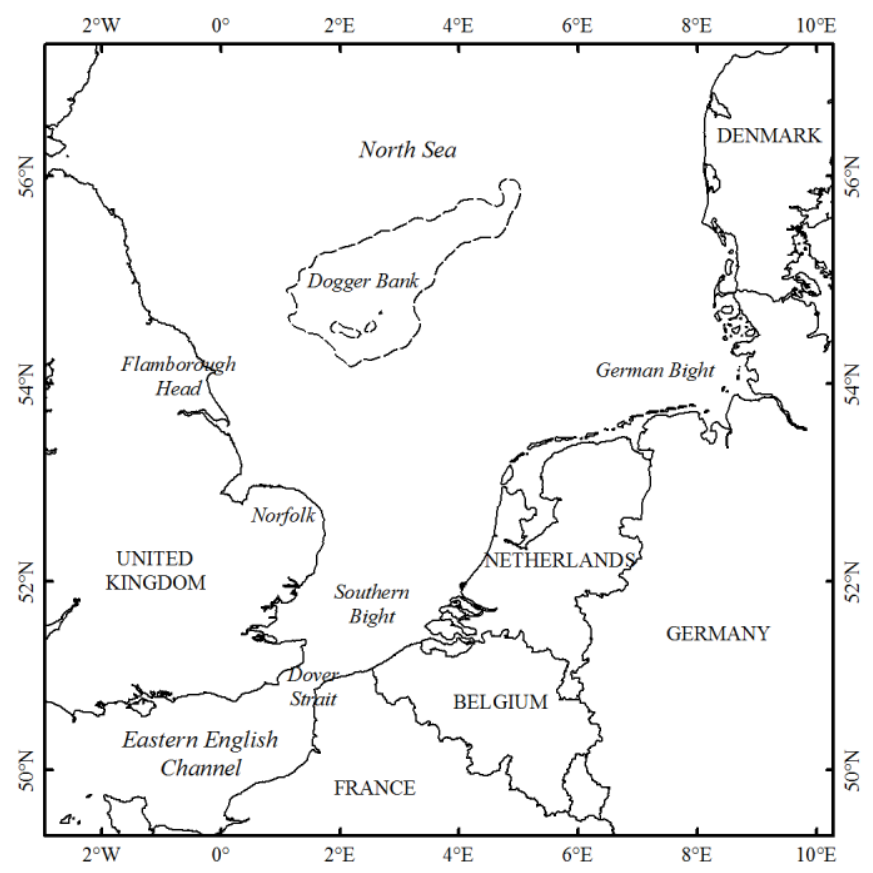

Figure 1: Study area, showing locations mentioned in the text. 


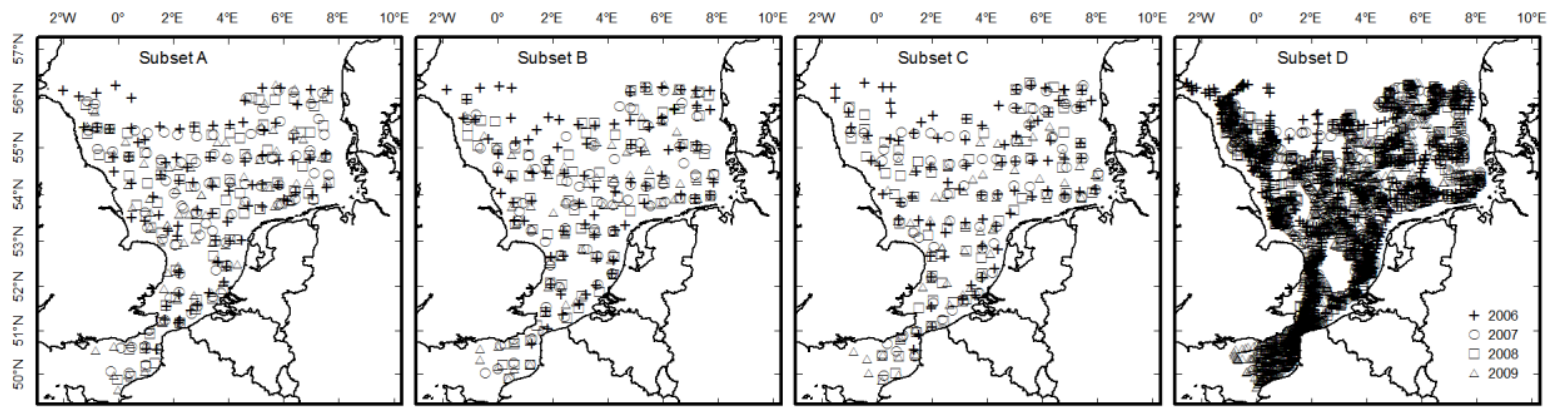

Figure 2: Sampling locations by CUFES (Continuous Underway Fish Eggs Sampler) during the French IBTS (International Bottom Trawl Survey), from 2006 to 2009. The three subsets A-B-C used for model calibration and the remaining dataset $\mathrm{D}$ used for model evaluation and selection are shown separately. 

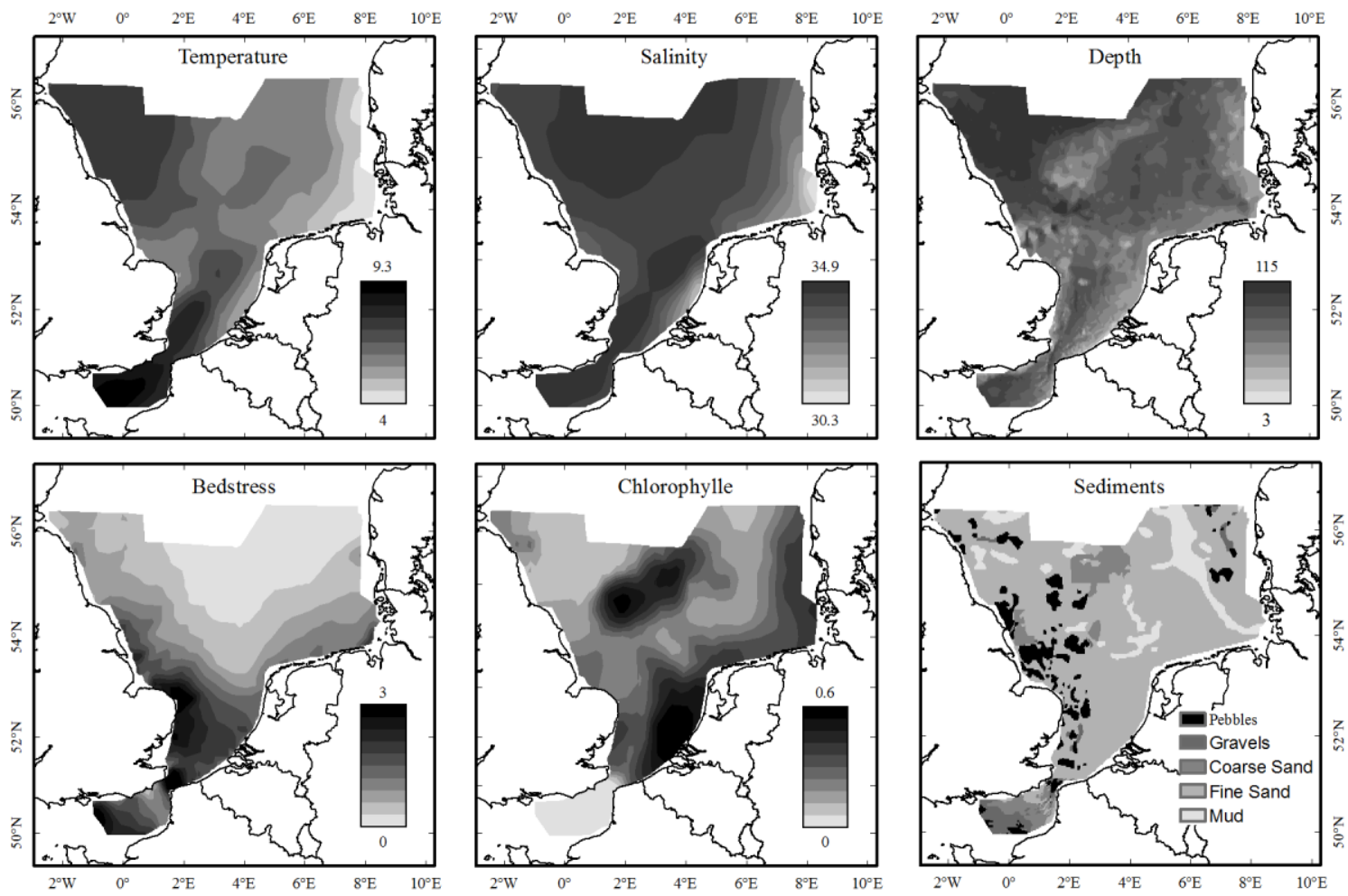

Figure 3: Maps of the five environmental variables (clockwise, starting from top-left): surface temperature $\left({ }^{\circ} \mathrm{C}\right)$, surface salinity (PSU), depth (m), bed stress $\left(\mathrm{N} \cdot \mathrm{m}^{2}{ }^{2}\right)$, surface chlorophylle $a$ concentration $\left(\mu \mathrm{g} . \mathrm{l}^{-1}\right)$, and seabed sediment types, used as predictors in the habitat modelling procedure. For temperature, salinity and chlorophyll $a$, maps show averages for the 20062009 winter period of the French IBTS. 

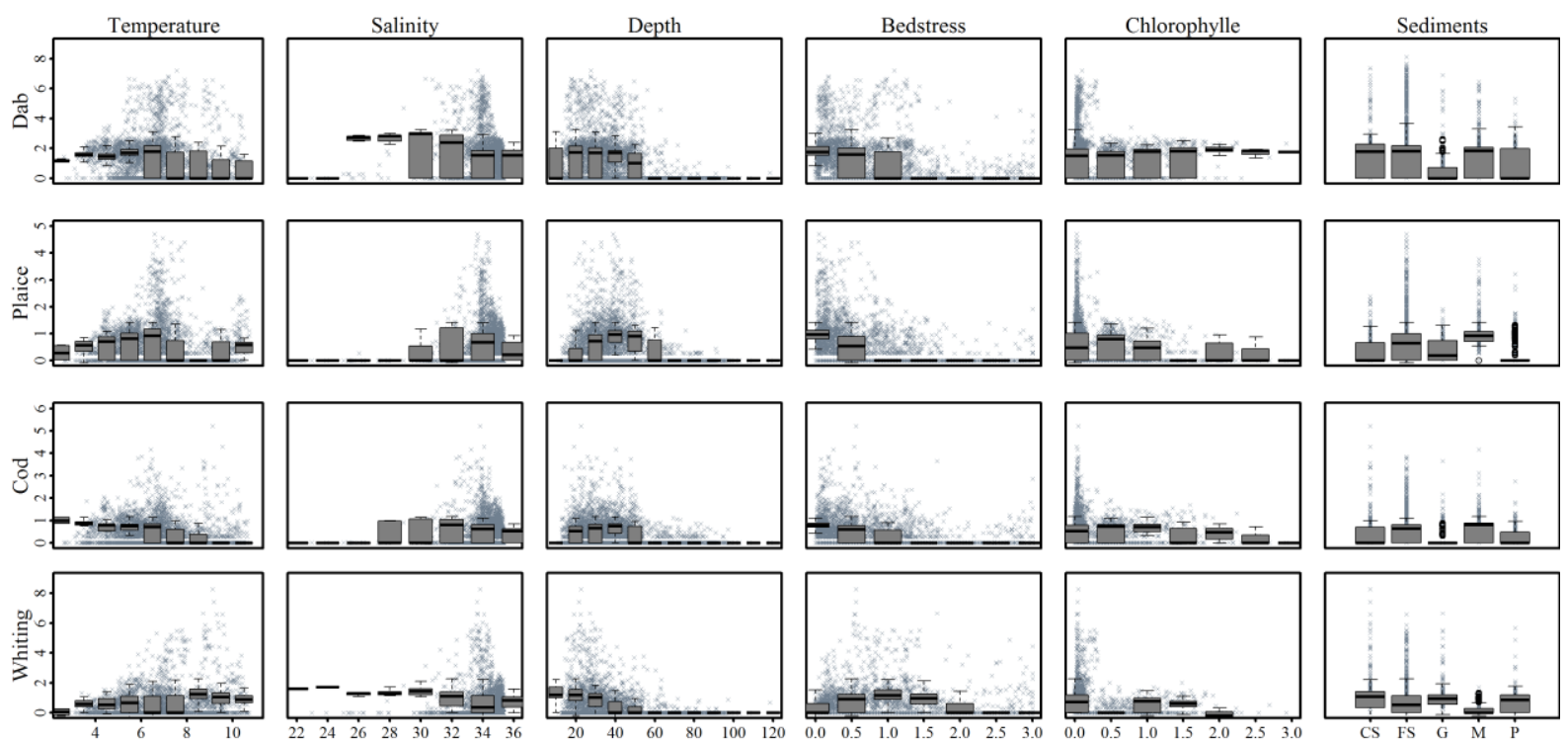

Figure 4: Plots showing predicted (boxplots) and observed (dots) egg densities, against each environmental variable (maps shown in Fig. 3). Predicted (delta model) and observed values are transformed using $\log _{10}(x+1)$, with $x=$ number of eggs per $20 \mathrm{~m}^{3}$. The lower, median and upper hinges of the boxplots show the $1^{\text {st }}, 2^{\text {nd }}$ and $3^{\text {rd }}$ quartiles of the predicted values, respectively. The boxplots' whiskers extend to the most extreme data point that is no more than 1.5 times the interquartile range. 

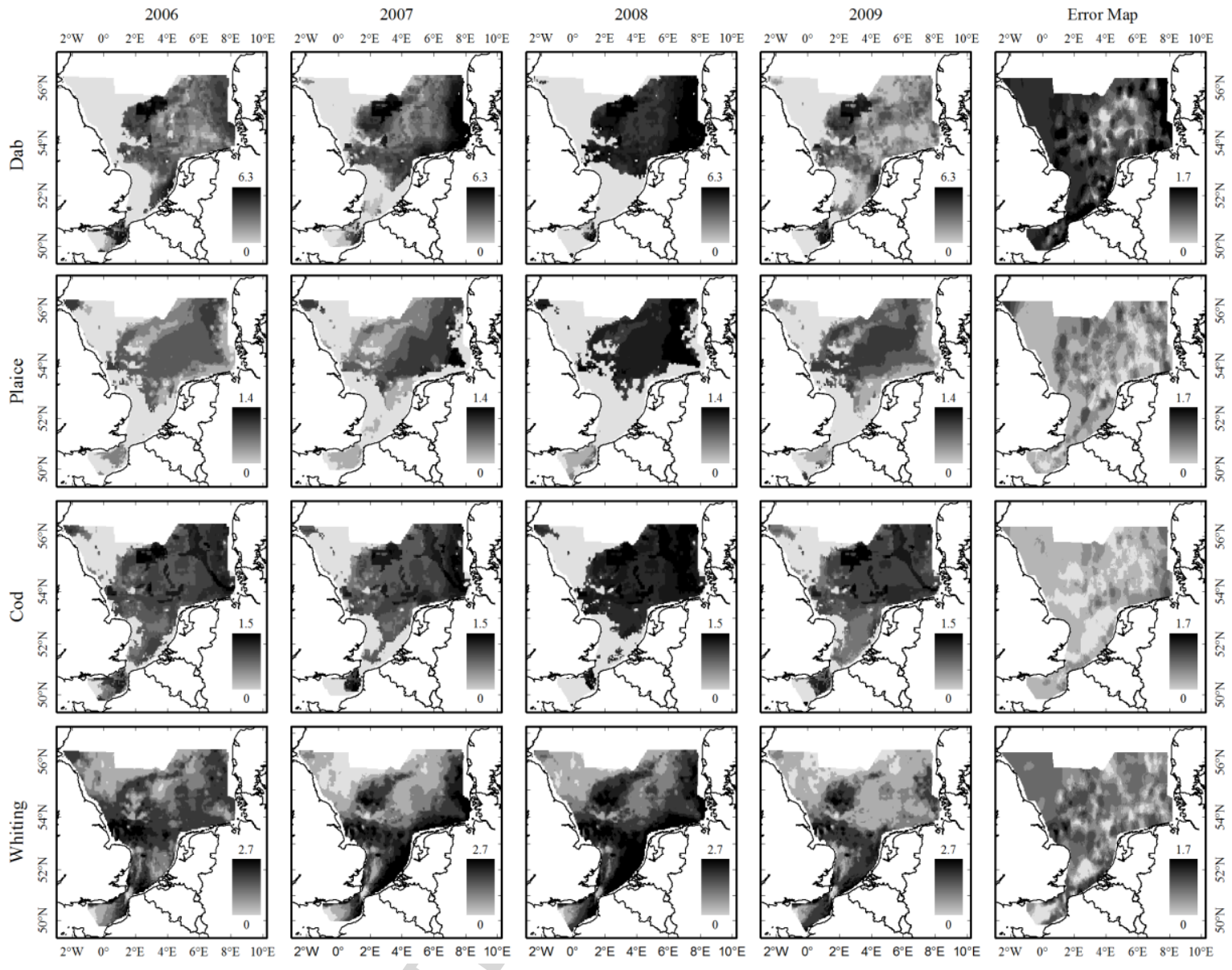

Figure 5: Winter spawning habitats of dab, plaice, cod and whiting, showing predicted egg densities (delta model) for each year between 2006 and 2009), and associated prediction errors. Egg densities are expressed as $\log _{10}(x+1)$, with $x=$ number of eggs per $20 \mathrm{~m}^{3}$. 

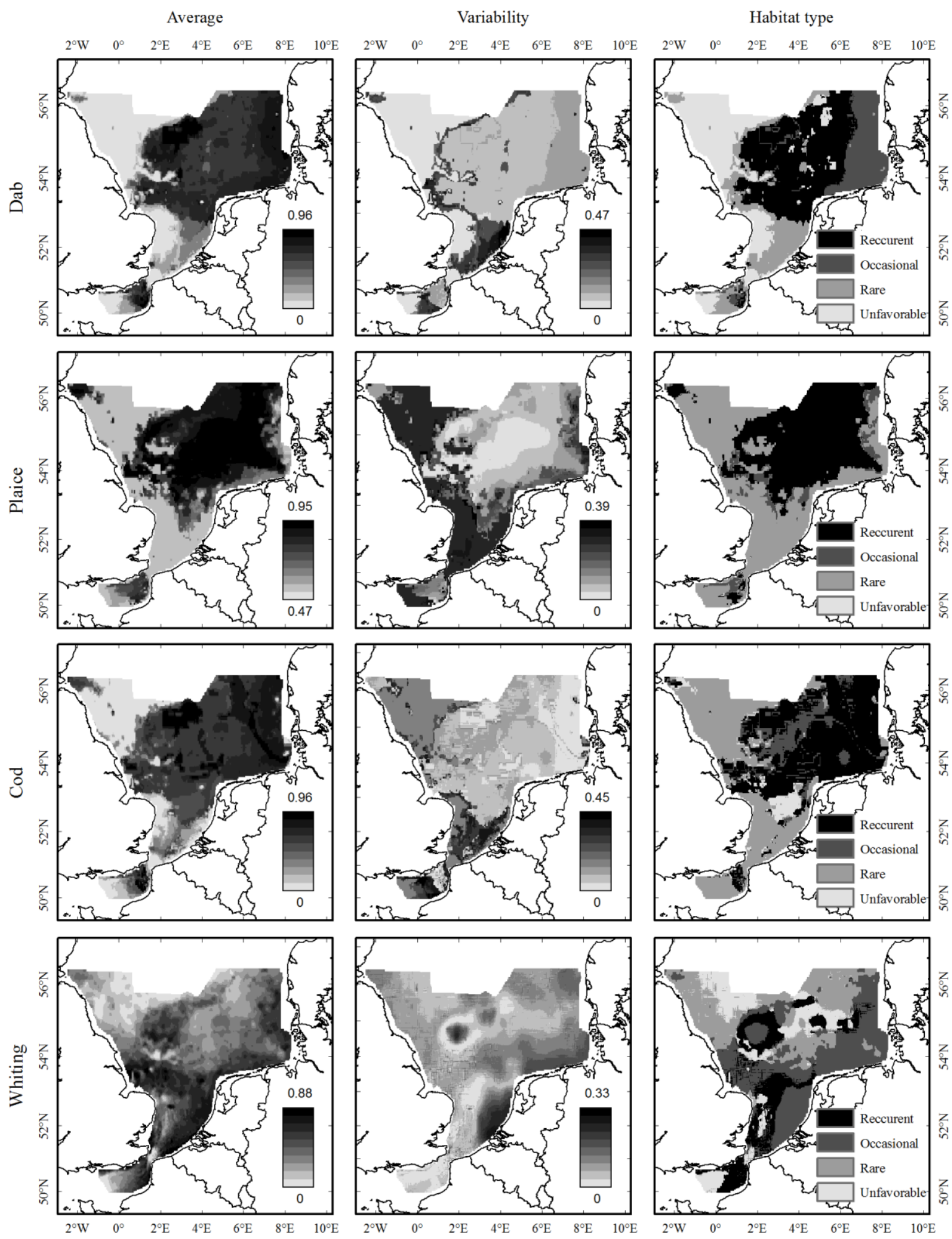

Figure 6: Maps of average, variability and type (recurrent, occasional, rare and unfavourable) of spawning habitat for dab, plaice, cod and whiting, for the period 2006 to 2009 (see main text for details). 


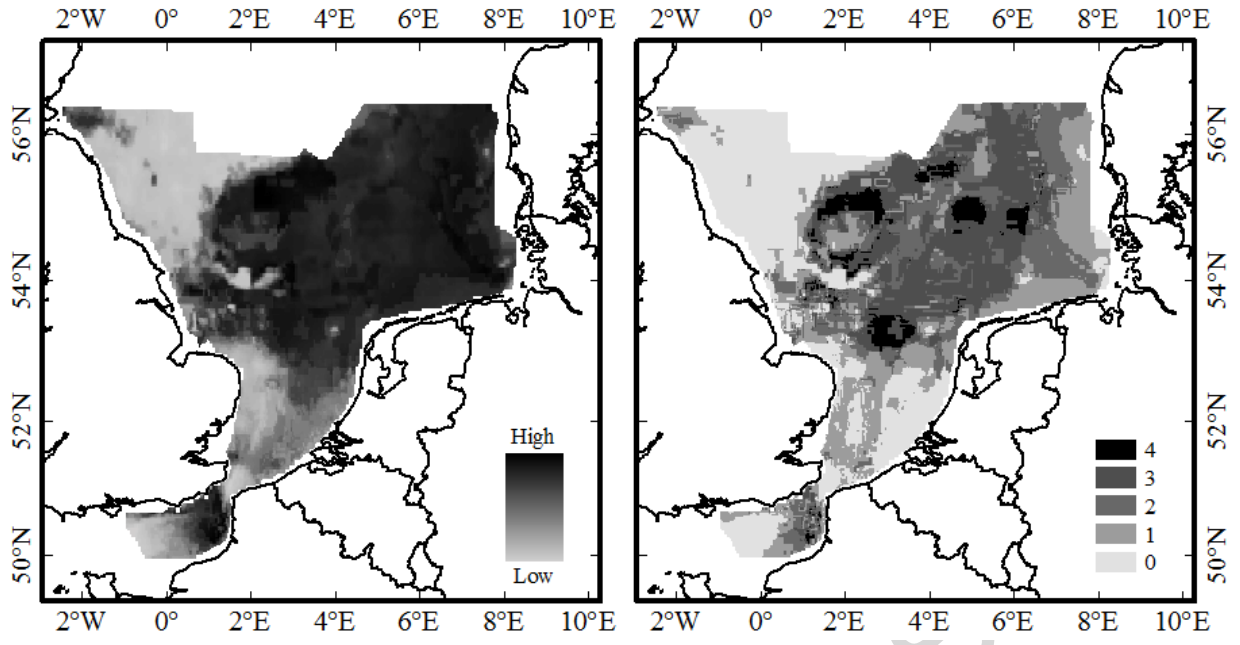

Figure 7: Mutispecific analysis (dab, plaice, cod and whiting). (left) Predicted spawning winter habitat highlighting areas that are the most suitable for the higher number of species. (right) Spawning recurrence frequency showing the number of species regularly using the area. 
Table 1: Start and end dates of the French IBTS (International Bottom Trawl Survey) surveys, and number of samples collected using CUFES (Continuous Underway Fish Egg Sampler). For model development, samples were split into four separate datasets (see text for details).

\begin{tabular}{lcccccc} 
Year & Start & End & Dataset A & Dataset B & Dataset C & Dataset D \\
\cline { 2 - 7 } $\mathbf{2 0 0 6}$ & 28 Jan & 21 Feb & 84 & 83 & 84 & 629 \\
$\mathbf{2 0 0 7}$ & 29 Jan & 22 Feb & 85 & 77 & 72 & 637 \\
$\mathbf{2 0 0 8}$ & 27 Jan & 21 Feb & 84 & 82 & 71 & 812 \\
$\mathbf{2 0 0 9}$ & 14 Jan & 13 Feb & 82 & 75 & 78 & 788
\end{tabular}

Table 2: Coefficients of Spearman's rank correlation for the four continuous environmental variables, and between them and fish eggs densities (plaice, dab, cod and whiting). Temp = sea surface temperature $\left({ }^{\circ} \mathrm{C}\right)$, Sal $=$ sea surface salinity $($ PSU), Depth $(\mathrm{m})$, Stress $=$ bed shear stress $\left(\mathrm{N} . \mathrm{m}^{-2}\right)$, Chloro $=$ chlorophyll $a$ concentration $\left(\mu \mathrm{g} .1^{-1}\right)$. Significance levels of $p$-values are shown as $* * *: p<0.001, * *: p<0.01, \mathrm{NS}: \mathrm{p}>0.05$.

\begin{tabular}{|c|c|c|c|c|c|c|c|c|c|}
\hline & Temp & Sal & Depth & Stress & & Plaice & Dab & Cod & Whiting \\
\hline Temp & & & & & & $-0.20^{\star \star \star}$ & $-0.28^{\star * *}$ & $-0.24^{* * *}$ & $0.08^{* * *}$ \\
\hline Sal & $0.30^{\star * \star}$ & & & & & $0.01 \mathrm{NS}$ & $-0.12^{\star * *}$ & $0.00 \mathrm{NS}$ & $0.01 \mathrm{NS}$ \\
\hline Depth & $0.37^{\star \star \star}$ & $0.34^{\star \star \star}$ & & & & $0.06^{\star \star *}$ & $-0.24^{\star \star *}$ & $-0.10^{\star \star \star}$ & $-0.22^{* * *}$ \\
\hline Stress & $0.27^{\star \star *}$ & $-0.01 \mathrm{NS}$ & $-0.28^{\star * *}$ & & & $-0.33^{* * *}$ & $-0.26^{* * *}$ & $-0.24^{\star \star *}$ & $0.17 \mathrm{NS}$ \\
\hline Chloro & $-0.51^{* * *}$ & $0.08^{* * *}$ & $-0.28^{* * *}$ & $0.03 \mathrm{NS}$ & & $-0.08^{\star * *}$ & $0.07^{* * *}$ & $0.05^{\star \star}$ & $-0.02^{* * *}$ \\
\hline
\end{tabular}


Table 3: For each species, final binomial occurrence (GLM b) and Gaussian (GLM p) models. Environmental variables are coded as follows: Temp $=$ sea surface temperature $\left({ }^{\circ} \mathrm{C}\right), \mathrm{Sal}=$ sea surface salinity (PSU), Depth (m), Stress $=$ bed shear stress $\left(\mathrm{N} \cdot \mathrm{m}^{-2}\right)$, Chloro $=$ sea surface chlorophyll $a$ concentration $a\left(\mu \mathrm{g} .1^{-1}\right)$, and seabed sediment types: fine sand (FS), gravel $(\mathrm{G})$, mud $(\mathrm{M})$ and pebbles $(\mathrm{P})$. Variables suffixed 2 indicate second order polynomial form.

\begin{tabular}{|c|c|c|c|c|c|c|c|c|c|c|c|c|c|c|c|c|}
\hline & & Intercept & Temp & Temp2 & Sal & Sal2 & Depth & Depth2 & Stress & Stress2 & Chloro & Chloro2 & $\mathrm{FS}$ & $\mathrm{G}$ & $\mathrm{M}$ & $\mathrm{P}$ \\
\hline \multirow[t]{2}{*}{ Plaice } & GLM b & -50.02 & -3.15 & 0.21 & 1.04 & -0.26 & 76.99 & -24.22 & -2.44 & -8.86 & -1.22 & 2.88 & 0.82 & 1.68 & 0.89 & 0.6 \\
\hline & GLM p & -12.55 & 0.69 & -0.05 & -0.38 & & 14.41 & -4.49 & & & & & & & & \\
\hline \multirow[t]{2}{*}{$\mathrm{Dab}$} & GLM b & -26.08 & -2.43 & 0.14 & 1.08 & & 51.9 & -18.1 & & -11.95 & -13.5 & 29.35 & & & & \\
\hline & GLM $p$ & -1.47 & 1.44 & -0.1 & -1.94 & 0.69 & 0.9 & -0.81 & -0.59 & -0.93 & 1.34 & -3.41 & -0.11 & -0.68 & 0.01 & -0.05 \\
\hline \multirow[t]{2}{*}{ Cod } & GLM b & -28.53 & & -0.02 & 0.83 & & 40.27 & -13.57 & & -7.7 & & & & & & \\
\hline & GLM $p$ & -5.04 & 0.04 & 0 & -0.45 & 0.1 & 8.13 & -2.71 & -0.65 & 0.5 & 0.57 & -1.43 & -0.05 & -0.25 & 0.05 & -0.18 \\
\hline \multirow[t]{2}{*}{ Whiting } & GLM b & -6.33 & -0.97 & 0.07 & 0.96 & -0.06 & 14.34 & -6.07 & 6.94 & -16.98 & -11.03 & 25.38 & 0.13 & 2.43 & 0.3 & 0.6 \\
\hline & GLM p & -1.03 & 0.84 & -0.05 & -0.24 & & & -0.69 & 3.09 & -6.61 & 5.75 & -17.71 & & & & \\
\hline
\end{tabular}


Table 4: Evaluation results for each species' binary model, showing the chosen calibration dataset (B or C), and selection criterion. Internal (using dataset A, B or C) and external (using dataset D) evaluation results are given (Adj-R $\left.{ }^{2}, A U C\right)$. Model residuals were tested for spatial autocorrelation using Morans' I (only the first lag's result is shown). Significance levels ( $p$ values) are shown as $* * *: p<0.001, * *: p<0.01, *: p<0.05$. The presence-absence cut-off values (used for model prediction) are given, along with the optimisation criteria retained (MSS: maximised sum of sensitivity and specificity).

\begin{tabular}{|c|c|c|c|c|c|c|c|c|c|}
\hline \multirow[b]{2}{*}{ Species } & \multicolumn{2}{|c|}{ Model construction } & \multicolumn{3}{|c|}{ Internal evaluation } & \multicolumn{2}{|c|}{$\begin{array}{c}\text { External } \\
\text { evaluation }\end{array}$} & \multicolumn{2}{|c|}{$\begin{array}{c}\text { Presence-absence } \\
\text { cut-off value } \\
\text { (estimated on full dataset) }\end{array}$} \\
\hline & $\begin{array}{c}\text { Calibration } \\
\text { dataset }\end{array}$ & $\begin{array}{c}\text { Selection } \\
\text { criteria }\end{array}$ & $\begin{array}{l}\text { Adj- } \\
\mathrm{R}^{2}\end{array}$ & AUC & $\begin{array}{c}\text { Morans' } \\
\text { I }\end{array}$ & $\begin{array}{l}\text { Adj- } \\
R^{2}\end{array}$ & AUC & $\begin{array}{l}\text { Selected } \\
\text { threshold }\end{array}$ & $\begin{array}{c}\text { Optimisation } \\
\text { criteria }\end{array}$ \\
\hline Plaice & $\mathrm{C}$ & Initial & 0.26 & $0.82 * * *$ & $0.09 \mathrm{NS}$ & 0.23 & $0.80 * * *$ & 0.4 & MSS \\
\hline $\mathrm{Dab}$ & B & BIC & 0.33 & $0.83 * * *$ & $0.28 * * *$ & 0.22 & $0.79 * * *$ & 0.56 & MSS \\
\hline Cod & $\mathrm{C}$ & $\mathrm{BIC}$ & 0.2 & $0.77^{* * *}$ & $0.05 \mathrm{NS}$ & 0.13 & $0.72 * * *$ & 0.51 & MSS \\
\hline Whiting & $\mathrm{C}$ & Initial & 0.12 & $0.74 * * *$ & $0.07 \mathrm{NS}$ & 0.04 & $0.7 * * *$ & 0.26 & MSS \\
\hline
\end{tabular}


Table 5: Evaluation results for each species's Gaussian model, showing the chosen calibration dataset (B or C), and selection criterion. Internal (using dataset A, B or C) and external (using dataset D) evaluation results are given (Adj- $\mathrm{R}^{2}$, Spearman's rank correlation test, Wilcoxon signed-rank test). Model residuals were tested for spatial autocorrelation using Morans' I (only the first lag's result is shown). Significance levels ( $p$-values) are shown as $* * *: p<$ 0.001, **: $p<0.01, *: p<0.05$, NS: $\mathrm{p} \geq 0.05$.

\begin{tabular}{|c|c|c|c|c|c|c|c|c|c|}
\hline \multirow[b]{2}{*}{ Species } & \multicolumn{2}{|c|}{ Model construction } & \multicolumn{4}{|c|}{ Internal evaluation } & \multicolumn{3}{|c|}{ External evaluation } \\
\hline & $\begin{array}{c}\text { Calibration } \\
\text { dataset }\end{array}$ & $\begin{array}{c}\text { Selection } \\
\text { criteria }\end{array}$ & $\begin{array}{l}\text { Adj- } \\
\text { R }^{2}\end{array}$ & Spearman & $\begin{array}{c}\text { Wilcoxon } \\
p \text {-value }\end{array}$ & $\begin{array}{c}\text { Morans' } \\
\text { I }\end{array}$ & $\begin{array}{l}\text { Adj- } \\
\mathrm{R}^{2}\end{array}$ & Spearman & $\begin{array}{c}\text { Wilcoxon } \\
p \text {-value }\end{array}$ \\
\hline Plaice & $\mathrm{B}$ & BIC & 0.63 & $0.4 * * *$ & NS & $0.15 \mathrm{NS}$ & 0.81 & $0.3 * * *$ & NS \\
\hline $\mathrm{Dab}$ & $\mathrm{C}$ & Initial & 0.85 & $0.3 * * *$ & NS & $0.15 *$ & 0.84 & $0.4 * * *$ & NS \\
\hline Cod & B & Initial & 0.79 & $0.2 * * *$ & NS & $0.02 \mathrm{NS}$ & 0.86 & $0.3 * * *$ & NS \\
\hline Whiting & B & AIC & 0.91 & $0.4 * * *$ & NS & $0.08 \mathrm{NS}$ & 0.94 & $0.4 * * *$ & NS \\
\hline
\end{tabular}


Table 6: Evaluation results for each species's delta model, showing Adj-R ${ }^{2}$, Spearman's rank correlation and Wilcoxon signed-rank test results, along with Confidence Intervals $(\mathrm{CI})$ obtained by bootstrapping. Significance levels ( $p$-values) are shown as ***: $p<0.001$, **: $p<$ $0.01, *: p<0.05, \mathrm{NS}: \mathrm{p} \geq 0.05$. Mean and range of absolute standardised residuals were computed for each model.

\begin{tabular}{|c|c|c|c|c|c|}
\hline \multirow[b]{2}{*}{ Species } & \multirow[b]{2}{*}{$\operatorname{Adj}-R^{2}(C I)$} & \multicolumn{2}{|c|}{ Spearman's correlation } & \multirow{2}{*}{$\begin{array}{l}\text { Wilcoxon } \\
\text { p-value }\end{array}$} & \multirow{2}{*}{$\begin{array}{l}\text { Absolute standardisec } \\
\text { residuals } \\
\text { Mean (Min-Max) }\end{array}$} \\
\hline & & rho $(\mathrm{CI})$ & $\mathrm{p}$-value & & \\
\hline Plaice & $0.84(0.82-0.88)$ & $0.49(0.46-0.51)$ & $* * *$ & & $0.4(0-1.79)$ \\
\hline Dab & $0.84(0.83-0.85)$ & $0.38(0.35-0.42)$ & $* * *$ & & $0.82(0-2.57)$ \\
\hline Cod & $0.85(0.81-1)$ & $0.34(0.31-0.37)$ & & & $0.35(0-1.44)$ \\
\hline Whiting & $0.96(0.95-0.99)$ & $0.31(0.29-0.34)$ & $F_{*}^{*}$ & $* * *$ & $0.51(0-2.13)$ \\
\hline
\end{tabular}


Figure 1: Study area, showing locations mentioned in the text.

Figure 2: Sampling locations by CUFES (Continuous Underway Fish Eggs Sampler) during the French IBTS (International Bottom Trawl Survey), from 2006 to 2009. The three subsets A-B-C used for model calibration and the remaining dataset D used for model evaluation and selection are shown separately.

Figure 3: Maps of the five environmental variables (clockwise, starting from top-left): surface temperature $\left({ }^{\circ} \mathrm{C}\right)$, surface salinity (PSU), depth (m), bed stress $\left(\mathrm{N} \cdot \mathrm{m}^{2}\right)$, surface chlorophylle $a$ concentration $\left(\mu \mathrm{g} . \mathrm{l}^{-1}\right)$, and seabed sediment types, used as predictors in the habitat modelling procedure. For temperature, salinity and chlorophyll $a$, maps show averages for the 20062009 winter period of the French IBTS.

Figure 4: Plots showing predicted (boxplots) and observed (dots) egg densities, against each environmental variable (maps shown in Fig. 3). Predicted (delta model) and observed values are transformed using $\log _{10}(x+1)$, with $\mathrm{x}=$ number of eggs per $20 \mathrm{~m}^{3}$. The lower, median and upper hinges of the boxplots show the $1^{\text {st }}, 2^{\text {nd }}$ and $3^{\text {rd }}$ quartiles of the predicted values, respectively. The boxplots' whiskers extend to the most extreme data point that is no more than 1.5 times the interquartile range.

Figure 5: Winter spawning habitats of dab, plaice, cod and whiting, showing predicted egg densities (delta model) for each year between 2006 and 2009), and associated prediction errors. Egg densities are expressed as $\log _{10}(x+1)$, with $x=$ number of eggs per $20 \mathrm{~m}^{3}$.

Figure 6: Maps of average, variability and type (recurrent, occasional, rare and unfavourable) of spawning habitat for dab, plaice, cod and whiting, for the period 2006 to 2009 (see main text for details).

Figure 7: Mutispecific analysis (dab, plaice, cod and whiting). (left) Predicted spawning winter habitat highlighting areas that are the most suitable for the higher number of species. (right) Spawning recurrence frequency showing the number of species regularly using the area. 


\section{HIGHLIGHTS}

- The spawning ground distributions of dab, plaice, cod and whiting are explored from 2006 to 2009 in the North Sea

- Spawning habitat models are developed by relating egg density to six environmental descriptors

- Predicted annual habitat maps highlight suitable spawning areas and their spatial variability

- Recurrent spawning grounds are delineated for each species

- Most suitable and temporally stable spawning areas are defined for use in marine spatial planning 